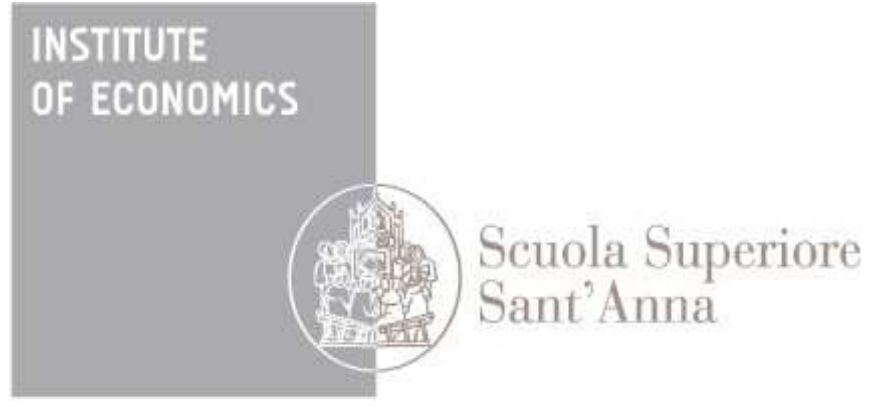

LEM | Laboratory of Economics and Management

Institute of Economics

Scuola Superiore Sant'Anna

Piazza Martiri della Libertà, 33 - 56127 Pisa, Italy ph. +3905088.33 .43$

institute.economics@sssup.it

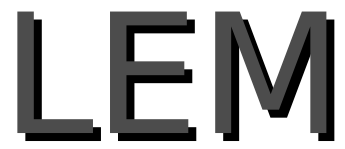

Working Paper Series

\title{
The micro patterns of export diversification under financial constraints
}

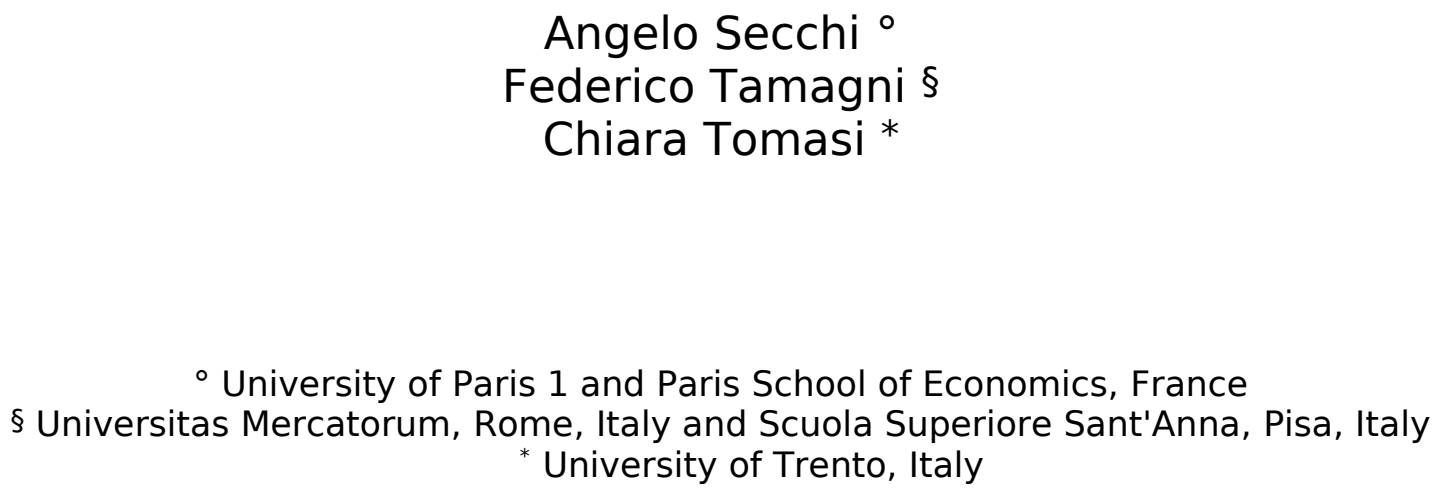




\title{
The micro patterns of export diversification under financial constraints*
}

\author{
Angelo Secchi ${ }^{\S}$, Federico Tamagni ${ }^{\ddagger}$, and Chiara Tomasi ${ }^{\circ}$ \\ §Paris School of Economics - Université of Paris 1 Panthéon Sorbonne, France and \\ LEM, Scuola Superiore Sant'Anna, Italy \\ Institute of Economics and LEM, Scuola Superiore Sant’Anna, Italy \\ 'University of Trento, Italy, and LEM, Scuola Superiore Sant'Anna, Italy
}

September 22, 2014

\begin{abstract}
Combining detailed data on export transactions and an informative firm level measure of financing constraints, this paper provides new evidence on the extent and dynamics of product and geographical diversification of constrained exporters. Financial constraints associates with: (i) narrower product/destination margins; (ii) higher probability to drop products and destinations, (iii) higher loss of export value associated to dropping product or destination markets; (iv) higher probability to discard products with relatively high share in firm total export values, and (v) higher likelihood to drop country markets that are bigger, richer, geographically closer and with a relatively high share in total firm export value.
\end{abstract}

JEL codes: F10, F14, F36, G20, G32, L25

Keywords: financial constraints, product-country extensive margins, product-country dropping, product attributes, gravity variables

${ }^{*}$ The present work has been possible thanks to a research agreement between the Italian Statistical Office (ISTAT) and the Scuola Superiore Sant'Anna. Angelo Secchi gratefully acknowledges the French National Research Agency, through the program Investissements d'Avenir, ANR-10-LABX 93-01. Chiara Tomasi gratefully acknowledges financial support by the Marie Curie Program Grant COFUND Provincia Autonoma di Trento. We also acknowledge financial support from the Institute for New Economic Thinking, INET inaugural grant \#220. 


\section{Introduction}

Recent evidence shows that an overwhelming share of international trade is conducted by large firms that export a broad variety of products to different destinations (Bernard et al., 2010, 2011; Goldberg et al., 2010). These firms vary their exported product mix within and across destination markets, in response to changes in the economic environment, by adding and dropping products and destination countries over time. Such adjustments of the intra-firm extensive margins play an important role, shaping firm and industry aggregate productivity, and with sizable consequences on trade volume.

The relevance of the phenomenon has spurred the investigation of the determinants of the firm choices to adjust the product and country mix over time. While previous studies emphasize the central role of firm attributes like size or productivity in mediating churning patterns, little is known about firms' behavior along the product and destination extensive margins in the context of adverse credit conditions. The evidence is scant and only focusing on the extent of diversification, while there is no attempt to study product and destination churning. Further, the role of financing problems is not explicitly considered in models of multi-product and multi-destination firms.

In the attempt to fill this gap, the present paper provides a new set of empirical results describing the role of limited access to external finance in shaping exporting behavior along product and destination extensive margins.

First, we confirm previous evidence that limited access to external financial resources associates with serving fewer countries and shipping a narrower range of products, hinting at the existence of relevant country-specific and product-specific fixed costs. Second, the work considers, for the first time, the role that financing problems play on the probability that firms drop products and destinations over time from their export portfolio. We find that financial constraints associate with a higher probability of dropping both products and destinations. This result suggests that external finance is needed not only to cover the fixed entry costs but also the recurrent costs of exporting. ${ }^{1}$ Furthermore, the paper shows that the share in overall export value of transactions associated with dropped products or destinations is higher for constrained firms. This result indicates that financing problems represent a relevant driver of resource reallocation within firms, with sizable detrimental consequences on firms exports and, potentially, on aggregate exports of sectors and countries. Finally, to further improve the understanding of the channels through which constraints influence the overall firm exports, the paper concludes by looking at within-firm choices about the type of products or destinations discarded by constrained firms. We find that, with respect to unconstrained companies, constrained firms tend to drop more those products which are relatively more "core" within their export bundle. Also, they tend to drop more frequently than unconstrained firms those destination countries which are relatively larger, richer, geographically closer and more important in terms of export values within the set of served countries.

The analysis is carried out by exploiting an original database of Italian manufacturing exporters that combines a firm-level dataset, including standard balance sheet information, with a custom-level

\footnotetext{
${ }^{1}$ We focus on the probability of dropping and not on the probability of adding new products or destinations motivated by our own evidence that differences between constrained and unconstrained firms are marked only for those firms that over time reduce the number of products and destinations, while no statistical difference is observed between constrained and unconstrained exporters that manage to overall increase the scope of diversification.
} 
dataset recording detailed information for each product and destination export transaction performed by each firm. A key feature of our study is that we proxy financial constraints by a credit rating index issued by an independent agency and available for all the firms in the dataset. This proxy is, indeed, useful to identify the point where a firm credit supply becomes inelastic, reflecting the decision of credit markets to make external credit a non-viable alternative for firms. The specific rating index available in this study, moreover, has widespread use within the Italian banking system and it is tightly linked to the actual supply and cost of credit in Italy.

Within the vast literature on firm heterogeneity in international trade, this article relates more directly to the growing literature on the determinants of firms' product and country churning decisions over time. Bernard et al. (2010) document that the choice of dropping a product is negatively correlated with the share of that product in a firm's overall exports and with the age of that good within a firm's product scope (see de Nardis and Pappalardo, 2009, for similar results on Italy). Timoshenko (2012) shows that the frequency of product adding and dropping declines with the tenure of the firm in a given export market. Albornoz et al. (2012) observe that entering and exiting from a market is more likely for first-time exporters than for experienced ones.

This paper is also strongly related to the emerging literature on the micro effects of credit and finance on international trade. Prior research on this topic shows theoretically and empirically that credit market imperfections severely restrict firms' export capacity. The empirical studies exploiting firm-level data show that financial constraints affect both the extensive and the intensive margin of exports, reducing firms' ability to start exporting and the volume of export. The role of financing constraints at the product/destination level is much less investigated. Muuls (2008) shows that less credit constrained firms export more products to more destinations, also documenting that firms with easier access to finance are more likely to expand the number of destinations they serve. Similarly, Askenazy et al. (2011) confirm that better financing conditions are positively associated with expansion and survival in export markets. Manova et al. (2011) show that limited access to outside capital restricts both the number of destinations served and the range of products exported.

\section{Data and definition of financial constraints}

In this section we describe the data, define our proxy of financial constraints and present descriptive statistics on our sample of Italian manufacturing exporters.

\section{Sources and sample}

Our analyses draw upon 2 different sources of data, combining information on export transaction flows with those reported in balance-sheets of manufacturing firms.

The Commercio Estero (COE) dataset is the official Italian dataset on foreign trade statistics. It is collected from custom registers by the Italian National Statistical Office (ISTAT) and reports separately the value (in Euros) and the quantity (in $\mathrm{Kg}$ ) involved in each export and import crossborder transaction performed by an Italian firm. It virtually covers the whole exports of Italy (Bernard 
et al., 2013). Traded products are classified at the six digit level of the Harmonized System (HS6), for a total of 5, 329 product categories exported in 236 different destination countries.

Export transaction data are linked with firm data from the Italian Company Account Data Service (Centrale dei Bilanci, CB) which collects annual administrative reports for all Italian limited liability firms. The long term institutional role of $\mathrm{CB}$ in gathering and sharing information on borrowers within the banking system ensures high data quality, limiting measurement error.

Our working sample is an open panel including a total of 66, 059 exporters over the years 20002003. It covers about $55 \%$ of all manufacturers that do export and around $85 \%$ of aggregate Italian exports. $^{2}$

\section{Financial constraints}

We base our assessment of firm-level financing constraints on a firm-specific credit rating score issued yearly by $\mathrm{CB}$. The index results from in-depth analysis conducted by professional analysts, combining hard and soft information on potential borrowers. ${ }^{3}$ The construction of the rating follows two steps. The first step produces a score based on a broad set of qualitative and quantitative variables. ${ }^{4} \mathrm{Next}, \mathrm{CB}$ analysts combine this score with additional information collected locally through direct contacts with the company and/or with the relevant market. The resulting index is given on a scale of 9 categories of creditworthiness: 1-high reliability, 2-reliability, 3-ample solvency, 4-solvency, 5-vulnerability, 6-high vulnerability, 7-risk, 8-high risk, and 9-extremely high risk.

The key difficulty in measuring financial constraints, shared by credit ratings as well as by other proxies in the literature, is that one would like to actually know when the credit supply faced by a firm becomes inelastic, so that external financing is un-viable for that firm. This theoretical definition does not have an easy empirical counterpart, because one does not typically observe the actual bank-firm contracting. To circumvent this difficulty, the proxies usually adopted in the literature, originated outside the micro-empirics of trade, are many and different, ranging from some balance-sheet variables though to be related with access to credit (cash-flow, leverage, investment-to cash or cash-to cash flow sensitivity), to more complex indexes combining different firm financial ratios, or based on surveys where firms are directly asked about their access to credit status. These measures all share a common identification assumption: that the shape of the firm credit supply is well reflected by the perception or actions of the firm (Farre-Mensa and Ljungqvist, 2013).

The main advantage of credit ratings is that they reflect more directly the credit markets decisions, allowing to identify where the firm credit supply becomes inelastic from the point of view of banks and credit institutions. And this yields a better identification, as it is indeed the credit market that ultimately defines the actual shape of the credit supply schedule. We are not the first following this

\footnotetext{
${ }^{2}$ Further details on the data sources and their coverage are available in the Technical Appendix. All the datasets were accessed at the ISTAT facilities in Rome and have been made available for work after careful screening to avoid disclosure of individual information.

${ }^{3}$ Soft information refers to any kind of data other than the publicly available information about the firm such as the availability of collateral or annual financial reports. Details available at http://www.cervedgroup.com.

${ }^{4}$ These include i) financial statement figures combined with geographical and sector-specific risk components; ii) qualitative indicators concerning a company's market share positioning, quality of governance and prospects for the future; iii) behavioral evaluation based on punctuality in payments to suppliers and default or other credit events.
} 
Table 1: PRODUCT AND GEOGRAPHICAL DIVERSIFICATION, 2003

\begin{tabular}{|c|c|c|c|c|}
\hline \multirow[b]{2}{*}{ Type of firm } & \multicolumn{2}{|r|}{ NFC } & \multicolumn{2}{|r|}{$\mathrm{FC}$} \\
\hline & Number of firms & Export value(Bill. euros) & Number of Firms & Export value(Bill. euros) \\
\hline Single product & $6777(17.2 \%)$ & $1.30(0.83 \%)$ & $895(27.8 \%)$ & $0.08(0.79 \%)$ \\
\hline Multiple product & $32602(82.8 \%)$ & $155.64(99.17 \%)$ & $2330(72.2 \%)$ & $10.13(99.21 \%)$ \\
\hline Single country & $8484(21.5 \%)$ & $0.94(0.60 \%)$ & $1112(34.5 \%)$ & $0.10(0.96 \%)$ \\
\hline Multiple country & $30895(78.5 \%)$ & $156(99.40 \%)$ & $2113(65.5 \%)$ & $10.12(99.11 \%)$ \\
\hline Total by FC status & 39379 & 156.94 & 3225 & 10.22 \\
\hline Perc. of whole sample & $92.43 \%$ & $93.88 \%$ & $7.57 \%$ & $6.12 \%$ \\
\hline
\end{tabular}

Notes: Number of exporting firms and total exports by financial status and distinguishing by multiple/single product/country firms. Percentages within FC groups in parenthesis. Figures computed on 2003 data.

strategy within trade studies. A similar approach based on credit scores is in Muuls (2008)'s study of Belgian firms, and in Wagner (2012)'s study of German firms. We are however the first exploiting this firm-level proxy to study dynamics along the product and destination margins. ${ }^{5}$

The rating index available to us has specific features that makes it a particularly well suited proxy for financial constraints. First, the $\mathrm{CB}$ rating is perceived as an official rating within the Italian credit system. It is therefore bench-marked by Italian banks in their internal procedures for the evaluation of potential borrowers, or even used as a key input in lending decisions. Previous empirical analyses confirm a tight link between the $\mathrm{CB}$ rating and the availability and the cost of external finance. Guiso et al. (2013) provide evidence that, ceteris paribus, bad ratings have a clear association with the cost of credit, while Panetta et al. (2009) show that it is unlikely that a firm with poor CB rating can ever receive any credit. Second, and relatedly, the link with banks' actual behavior is crucial in the attempt to capture credit conditions in Italy, where bank credit is by far the primar source of external credit for firms. In fact, Italian capital and bond markets are quite small compared to other major countries. ${ }^{6}$ Third, it is also important that the CB index, due to the combination of soft and hard information, does not merely reflect firms' performance and characteristics, but it also encompasses a complex and rich informational content. In line with this, previous empirical analyses (Bottazzi et al., 2008, 2014) show that an important fraction of highly productive, highly profitable and fast growing firms indeed receive poor scores. ${ }^{7}$

Notwithstanding the potential interest in considering the graduation of access to credit implicitly attached to the different rating scores, previous empirical studies (cfr. again Farre-Mensa and

\footnotetext{
${ }^{5}$ Due to the mentioned impossibility to observe the actual firm-bank relationship, ratings and other common proxies of FCs do not say anything about whether the difficulty to resort to external finance reflects a wrong or a correct decision from credit markets. For instance, poorly rated firms are firms judged as high risk and not worth receiving credit, but one cannot precisely know if that was a myopic choice failing to consider future growth potentials or a correct identification of a lemon firm. In this sense, most of the typically available measures of credit constraints, including those based on direct answers in surveys, measure difficulty in accessing credit or more generally the presence of financing problems rather than the degree of market imperfection.

${ }^{6}$ See Panetta (2013).

${ }^{7}$ This reinforces the idea that credit ratings reflect some actual behavior of credit markets, capturing more than the mere balance-sheets based information.
} 


\begin{tabular}{lccc}
\hline Export margin & & Test statistics & P-value \\
\hline & & -23.24 & $<0.0001$ \\
$\ln$ \#Products & & -28.26 & $<0.0001$ \\
$\ln$ \#Countries & & -7.19 & $<0.0001$ \\
& & -6.96 & $<0.0001$ \\
& & 0.05 & 0.96 \\
& & & \\
& (conditional on negative values) & & \\
& (conditional on positive values) & -7.58 & $<0.0001$ \\
& & -10.62 & $<0.0001$ \\
& (conditional on negative values) & 0.75 & 0.45 \\
\hline
\end{tabular}

Notes: Fligner and Policello (1981) test of stochastic dominance.

Ljungqvist, 2013) show that only firms with quite poor ratings are likely to face an inelastic credit supply schedule. We therefore exploit the CB index by building a financial constraints dummy (FC) that equals 1 if a firm is rated 8 or 9 , and 0 otherwise (we sometimes refer as NFC firms the firms with $\mathrm{FC}=0) .{ }^{8}$ In the analysis we will use the 1-year lagged value of the FC dummy as our main regressor. Indeed the rating scores are updated at the end of each year, and it is therefore the rating in $t-1$ that is relevant for credit suppliers' current decisions on credit provision. ${ }^{9}$

Table 1 presents the number of exporters and the total exports for NFC and FC firms in 2003. Around $8 \%$ of exporters are classified as financially constrained and they account for $6 \%$ of total exports. Our data also confirm the large predominance of multi-product and multi-country firms observed in other countries, accounting for substantially the total of the export flows. About $83 \%$ of unconstrained firms export more than one product and about $79 \%$ serve more than one country. These percentage shares are slightly smaller within the constrained firms group. This is a first hint that financial constraints associate with a more restricted ability to diversify products and destinations.

\section{Descriptive Evidence}

In this section we provide an assessment of the relationship between financial constraints and export diversification through distributional comparisons across FC and NFC firms. We look at three complementary dimensions of diversification along the product and the destination margins.

First, top panels of Figure 1 look at the extent of diversification. We report the Complementary

\footnotetext{
${ }^{8}$ The choice reflects findings in previous Italian studies exploiting the CB ratings. Guiso et al. (2013) broke down the sample in three categories, inserting an intermediate class of Mildly Financially Constrained (MFC) firms, defined as those rated 4 to 6 . In their wage regression, the dummy for the medium score does not have a direct effect on the dependent variable. Bottazzi et al. (2008) and Bottazzi et al. (2014) find similar results when inserting a mid-constrained category in their analysis of productivity, profitability and growth dynamics of Italian firms.

${ }^{9}$ There is some variability in firms' financial status between different time lags. Looking at the transition matrix we observe that between $t$ and $t+1$ the percentage of firms moving from NFC to FC is $3.9 \%$ while those moving from FC to NFC is $47.2 \%$. Taking a bigger time lag, between $t$ and $t+3$, the percentage of changes between NFC and FC increases to $9.5 \%$ and that of changes from FC to NFC raises to $64.0 \%$.
} 

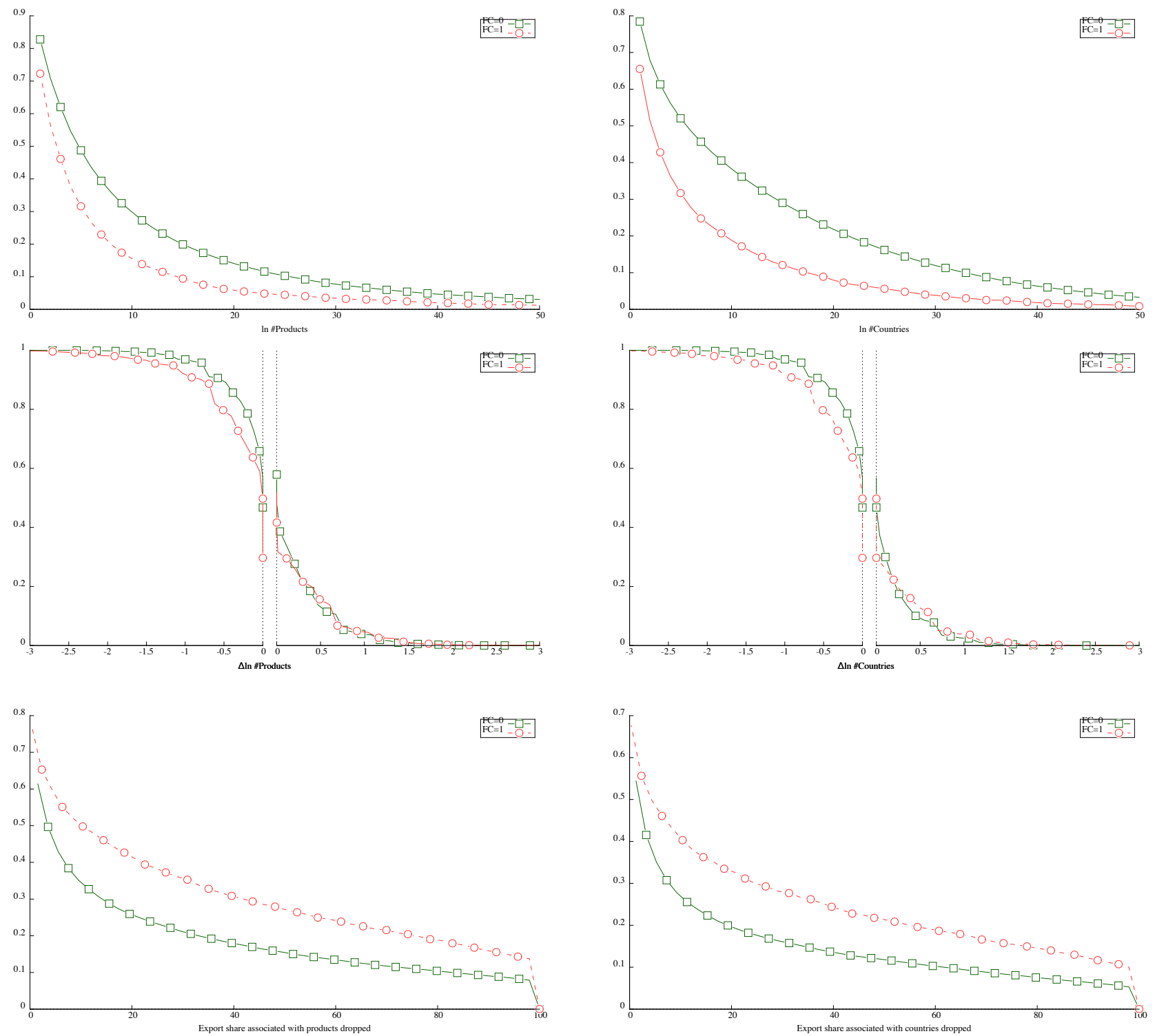

Figure 1: COMPLEMENTARY CUMULATIVE DISTRIBUTION FUNCTIONS (CCDF) BY FINANCIAL CONSTRAINTS STATUS.

Notes: Top panel reports the CCDF of the number of products exported (left) and the number of countries served (right) by unconstrained (thin line) and constrained (thick line) exporters in 2003. Middle panel reports the CCDF of the (log) difference of the number of products exported (left) and of the number of countries served (right) by unconstrained (thin line) and constrained (thick line) exporters between 2002 and 2003. Bottom panel reports the CCDF of the share of export lost by products (left) and countries (right) dropped by unconstrained (thin line) and constrained (thick line) exporters in 2003. 
Cumulative Distribution Function (CCDF), defined as $1-\operatorname{Pr}(X \leq x)$, for the number of products exported (left) and the number of countries served (right), by unconstrained (thin line) and constrained (thick line) exporters in 2003. ${ }^{10}$ In line with previous studies, we observe that FC firms export a smaller set of products and cover a smaller number of destinations. The graphical impression is validated by means of a Fligner-Policello (hereafter FP) test of stochastic dominance reported in Table 2. The null hypothesis is that the probability that a NFC firm displays a higher value of a given attribute, as compared with a FC one, is equal 1/2. A negative (positive) value of the test statistics implies that this probability is higher (lower) than 1/2. (see the Technical Appendix for details on the test). The test statistics and the associated p-value confirm that the NFC firms distributions dominate the distributions estimated for FC firms.

Second, in the middle panels of Figure 1, we explore the time changes in the overall firm extent of diversification. We show the CCDF of the (log) differences, computed between 2002 and 2003, of the number of products exported ( $\Delta \ln$ \#Products, left) and of the number of countries served $(\Delta \ln$ \#Countries, right) by unconstrained (thin line) and constrained (thick line) exporters. ${ }^{11}$ The results provide evidence of diverging patterns characterizing expansions vs. contractions of the margins. The distributions obtained for FC firms display a more pronounced skeweness both for products (skewness is -0.43 for FC firms and -0.04 for NFC firms) and for countries (skewness is -0.31 for FC firms, and -0.74 for NFC firms). However, these asymmetries only regard negative tails, while the right part of the two distributions does not change with the FC status. The FP tests (in Table 2) confirm that the two groups display statistically significant differences only in the negative tail of the distribution. This result provides suggestive evidence that financing problems matter more when a firm chooses or is forced to drop products and destinations, while they do not seem to strongly associate with the decision to add new products or new destination markets.

Finally, in the bottom panels of Figure 1, we look at the distribution of percentage shares of firm export value associated with what we label hereafter as "to-be-dropped" products and destinations. That is, we compute the export value associated to the transactions in all products exported or countries served in a given year but not exported or served any more in the subsequent year, as percentage share of the total value of exports performed by a firm in the initial year. We report results by unconstrained (thin line) and constrained (thick line) exporters between 2002 and 2003, as a share of total exports in 2002. The evidence, again confirmed by the FP test, is clear-cut: the share of to-be-dropped products and destination countries is much higher among FC than among NFC firms. On average, the export share loss associated to dropped products is $42.3 \%$ for NFC firms, whereas it is $49 \%$ for FC firms (it is $42.6 \%$ on the whole sample). Analogously, the average export loss associated to dropped destinations is $21.9 \%$ and $32.2 \%$ of total exports for NFC and FC firms respectively $(22.3 \%$ across all firms). ${ }^{12}$

Even with all the caveats associated with an unconditional and univariate analysis, the evidence of

\footnotetext{
${ }^{10}$ Results are identical in other years.

${ }^{11}$ Note that here we focus on the net adding and dropping dynamics and we do not investigate possible differences in the underlying gross flows.

${ }^{12}$ These figures are computed on the observations for "surviving firms", i.e. firms that export in at least one product or one country between two consecutive years. This keeps comparability with the regression analysis in the following section.
} 
this section supports the idea that financial constraints associate with poorer export performance along both product and destination extensive margins, and also play a role in terms of dropping decisions and in terms of the consequences that dropping products or destinations exert on a firm's total export value. The next Section 4 further investigates these conclusions by means of regression analysis.

\section{Regression analysis}

We perform three sets of exercises, investigating the relationship of the FC status with the number of products or destinations in the export portfolio, with a firm's decision to drop a product or a country, and with the share of to-be-dropped products in the overall export value of firms. All the analyses control for a set of potentially relevant firm-level characteristics, and exploit the product and destination variation of the data to control for unobserved heterogeneity at different levels. Also, we check that results are robust to potential self-selection into export.

We will not be able to give a complete causal interpretation to our results since financial constraints and the various dimension of export performance that we use as dependent variables might be jointly determined. Endogeneity problems might also arise due to standard omitted variables or measurement error issues. ${ }^{13}$ However, we are confident that potential endogeneity is reduced, for a number of reasons. First, export performance measures do not enter in the construction of the CB ratings. Second, firm characteristics included as controls capture the most important factors affecting both constraints and export performance. Third, both controls and the indicator of FC status enter with a lag, thus reducing simultaneity. Finally, by adding full sets of firm-, product- or destinationfixed effects, or combinations of the former, the estimated effect of financial constraints mainly relies upon a relatively clean source of identification, that is the within-firm change of FC status over time keeping product or destination markets fixed. ${ }^{14}$

\section{Product and Country extensive margins}

The few existing empirical studies conclude that financial constraints hamper firms' capacity to operate along the product scope and to expand their geographical diversification (Manova et al., 2011; Muuls, 2008; Askenazy et al., 2011). The economic intuition behind these results is that external finance can be needed to meet fixed costs of exporting, with the latter being either product or country specific, as suggested by Manova et al. (2011). Because constrained firms have lower ability to finance these costs, they sell fewer goods and reach less markets than in absence of financial constraints. The distributional analysis of the previous section suggests that this is also the case for Italian exporters.

We start exploring the relationship between financial constraints and the product margin, estimating the following regression

$$
\ln \text { Products }_{f, t}=\alpha+\gamma F C_{f, t-1}+\boldsymbol{\beta Z}_{f, t-1}+\mu_{f}+\epsilon_{f, t} \quad,
$$

\footnotetext{
${ }^{13}$ For instance, it can be that our size or productivity proxies are mis-measured. Banks are usually more likely to provide credit to larger and more productive firms, which in turn are known to have superior export performance.

${ }^{14}$ Notice however that in estimating the following firm level equations (1) and (3) we were able to adopt an explicit IV strategy, following Minetti and Zhu (2011). Our main results are confirmed (see Technical Apppendix).
} 
Table 3: FINANCIAL CONSTRAINTS AND PRODUCT-COUNTRY EXTENSIVE MARGIN

\begin{tabular}{|c|c|c|c|c|c|c|}
\hline \multirow[t]{3}{*}{ Dependent variable } & \multicolumn{2}{|c|}{$\ln \#$ Products $_{f, t}$} & \multirow{3}{*}{$\begin{array}{c}\ln \# \text { Products } s_{f d, t} \\
\text { (3) } \\
\text { FE }\end{array}$} & \multicolumn{2}{|c|}{$\ln \#$ Countries $_{f, t}$} & \multirow{3}{*}{$\begin{array}{c}\ln \# \text { Countries }_{f d, t} \\
\text { (6) } \\
\text { FE }\end{array}$} \\
\hline & $(1)$ & (2) & & (4) & (5) & \\
\hline & $\mathrm{FE}$ & Selection & & $\mathrm{FE}$ & Selection & \\
\hline \multirow{2}{*}{$F C_{f, t-1}$} & $-0.042 * *$ & $-0.037 * *$ & $-0.022 * * *$ & $-0.031 * *$ & $-0.043 * *$ & 0.003 \\
\hline & $(0.017)$ & $(0.016)$ & $(0.007)$ & $(0.015)$ & $(0.016)$ & 0.007 \\
\hline \multirow{2}{*}{$\ln T F P_{f, t-1}$} & $0.024 *$ & 0.012 & -0.003 & $0.036 * * *$ & $0.022 * *$ & $0.008 *$ \\
\hline & $(0.012)$ & $(0.011)$ & $(0.004)$ & $(0.011)$ & $(0.011)$ & 0.004 \\
\hline \multirow[t]{2}{*}{$\ln E m p l_{f, t-1}$} & $0.065^{* * *}$ & $0.026^{* *}$ & 0.003 & $0.088 * * *$ & $0.047 * *$ & $0.014 * * *$ \\
\hline & $(0.012)$ & $(0.012)$ & $(0.004)$ & $(0.011)$ & $(0.012)$ & 0.005 \\
\hline \multirow[t]{2}{*}{$\ln A g e_{f, t}$} & -0.02 & $-0.120 * *$ & -0.007 & 0.043 & $-0.110 * *$ & 0.023 \\
\hline & $(0.045)$ & $(0.046)$ & $(0.014)$ & $(0.040)$ & $(0.049)$ & 0.016 \\
\hline \multirow{2}{*}{$\ln$ Assets $_{f, t-1}$} & $0.171 * * *$ & $0.190 * * *$ & $0.054 * * *$ & $0.172 * * *$ & $0.133 * * *$ & $0.032 * * *$ \\
\hline & $(0.018)$ & $(0.016)$ & $(0.005)$ & $(0.016)$ & $(0.017)$ & 0.007 \\
\hline \multirow[t]{2}{*}{$\ln G O M_{f, t-1}$} & -0.001 & -0.001 & 0.0001 & -0.001 & -0.003 & -0.0002 \\
\hline & $(0.003)$ & $(0.003)$ & $(0.001)$ & $(0.002)$ & $(0.003)$ & 0.001 \\
\hline Year FE & Yes & Yes & Yes & Yes & Yes & Yes \\
\hline Firm FE & Yes & Yes & Yes & Yes & Yes & Yes \\
\hline Country FE & No & No & Yes & & & \\
\hline Product FE & & & & No & No & Yes \\
\hline Adj. $R^{2}$ & 0.885 & - & 0.356 & 0.934 & - & 0.240 \\
\hline N.Observations & 95,075 & 95,075 & $1,224,526$ & 95,075 & 95,075 & $1,086,635$ \\
\hline
\end{tabular}

Note: Regression using data on 2001-2003. All the regressions include a constant term. Robust standard errors in parenthesis, clustered at firm level. Asterisks denote significance levels $(* * *: \mathrm{p}<1 \% ; * *: \mathrm{p}<5 \% ; * \mathrm{p}<10 \%)$.

where $F C$ is the dummy for constrained firms in $t-1, \mu_{f}$ is a firm fixed-effect and $\mathbf{Z}$ is a vector of lagged, time-varying firm level controls. These include proxies for productivity, size and age, and proxies for financial side factors that might interact with access to external financing captured by the FC dummy variable. We calculate Total Factor Productivity ( $T F P$ ) following the IV-GMM modified Levinsohn-Petrin procedure proposed in Wooldridge (2009) using material costs as a proxy for intermediate inputs. We use the number of employees (Employees) as a proxy for firm size, and compute age (Age) by year of foundation. Financial factors include the Gross Operating Margin as a proxy for internal resources and total Assets as a proxy for collateral. ${ }^{15}$

We are primarily interested in $\gamma$, which reflects the conditional correlation between our measure of financial constraints and the extent of product diversification in foreign markets. The estimation results are presented in Table 3.

In column 1 we report estimates obtained with firm fixed effects, thus identifying $\gamma$ through firmspecific changes of the rating score over time. The estimated coefficient points out a $4.1 \%(\gamma=$ $-0.042)$ reduction in the number of products. The results on the control variables are in line with the expectations from theory and previous studies, and reveal that more productive, larger and more collateralised firms export more products.

In column 2 we address potential bias due to self-selection into export. We employ the modified

\footnotetext{
${ }^{15}$ Nominal variables are deflated with appropriate sectoral price indexes collected by the Italian statistical office. Complete deflator series are available only at the 2-digit level. We therefore perform deflation at this level of aggregation. The base year is 2000. Given the relatively high frequency of negative GOM in the sample, negative values of GOM have been transformed to one before taking logs.
} 
Heckman-type procedure developed by Semykina and Wooldridge (2010). The main advantage of this procedure is that it allows to control for arbitrary correlations between unobserved heterogeneity and regressors in both the equation of main interest and the underlying selection equation. ${ }^{16}$ It nevertheless requires an exclusion restriction, for which we need a proxy of sunk of entry into exports. Following Bernard and Jensen (2004) and Bernard et al. (2013), for each firm $f$, we define a proxy $\left(\right.$ ExpCost $\left._{f}\right)$ computed as the minimum between export entry and exit rates in the local labour system (LLSs) wherein a firm is located. LLSs are geographical areas defined by the Italian Statistical Office as an aggregation of municipalities according to the degree of connectivity of labour market, and thus identifying local areas where production-labour relationships are tight. Such tight connections at the local level imply activities such as sharing same trade services, accessing pools of established distribution networks, exploiting knowledge of neighbors' experience in dealing with foreign contracts and foreign legislation, and possibly other factors that all tend to facilitate the entry into export markets. Therefore, a higher rate of entry into or exit from export markets within LLSs indicates lower sunk costs of exporting. The estimated FC coefficient is still negative and significant, with magnitude comparable to the results from the baseline FE model. ${ }^{17}$

Finally, in column 3, we check that our results are not driven by unobserved country characteristics that might influence a firm's product scope in that destination market. We exploit the firm-destination level variability of our dataset by studying the number of products that firms export bilaterally to a given destination. The regression equation becomes

$$
\ln \# \text { Products }_{f d, t}=\alpha+\gamma F C_{f, t-1}+\boldsymbol{\beta} \mathbf{Z}_{f, t-1}+\mu_{f}+\mu_{d}+\epsilon_{f d, t}
$$

where we add a destination country fixed effect, $\mu_{d}$. The coefficient $\gamma$ is therefore identified solely from the variation of FC status that is idiosyncratic to individual firm-destination pairs. Results confirm the negative relationship between constraints and the number of products exported.

Next, we replicate the analysis to investigate the association between financing constraints and the destination margin. Our main equations of interest are a firm-level and a firm-product level regression

$$
\begin{aligned}
& \ln \# \text { Countries }_{f, t}=\alpha+\gamma F C_{f, t-1}+\boldsymbol{\beta Z}_{f, t-1}+\mu_{f}+\epsilon_{f, t} \\
& \ln \# \text { Countries }_{f p, t}=\alpha+\gamma F C_{f, t-1}+\boldsymbol{\beta} \mathbf{Z}_{f, t-1}+\mu_{f}+\mu_{p}+\epsilon_{f p, t}
\end{aligned}
$$

where $\ln \#$ Countries $_{f, t}$ and $\ln \#$ Countries $_{f, t}$ denote the $(\log )$ number of destinations and the (log) number of destinations by product served by firm $f$, respectively. While the first specification includes only firm fixed effect $\left(\mu_{f}\right)$, the second also considers product fixed effects $\left(\mu_{p}\right)$. The coefficient $\gamma$ on the FC dummy is therefore identified through variation of FC status over time within firm in the first equation, and through variation over time within firm-and-product in the second equation.

Columns 4-5 of Table 3 present the results of various estimation strategies applied to equa-

\footnotetext{
${ }^{16}$ Because of the presence of unobserved effects in the selection equation, just adding the inverse Mills ratio and simply using Fixed Effects does not produce consistent estimates of the outcome equation. A solution à la Mundlak is available via adding time averages of all the exogenous explanatory variables appearing in both the main and the selection equation. See Semykina and Wooldridge (2010) for details of the procedure.

${ }^{17}$ The significance of the coefficient on the inverse Mills ratio (non reported) confirms that selection is indeed an issue.
} 
tion (3). The regression with firm fixed-effects (column 4) reveals that a within-firm change from unconstrained to constrained category entails, on average, a reduction of about $3 \%$ in the number of destination countries that a firm can serve. Results are robust if we again implement the Semykina and Wooldridge (2010) procedure to control for selection (column 5). Results on controls in all these models reflect what we have found above for the product margin. However, the estimated $\gamma$ looses statistical significance when we estimate equation (4), with firm and product fixed effects (column 6). This result suggests that the negative correlation between the FC dummy and the extent of geographical diversification of manufacturing firms is ultimately driven by the corresponding extent of product diversification.

All these findings together confirm previous evidence that access to finance plays an important role in firm export diversification, beyond other traditional firm-level drivers such as size or productivity. Constrained firms display a narrower extent of diversification, along both the product and geographical margins of exports, suggesting that financial frictions are binding with respect to the fixed costs that exporting firms face whenever they enter a product or a country.

\section{Product and country dropping}

We now move to investigate the role of constraints in the decision to discard products or countries from the export bundle, a decision that our descriptive investigations have shown to be sensitive to FCs.

A key prediction of recent models explaining the process of within-firm rearrangement of products and destinations portfolios (Bernard et al., 2010, 2011) is that diversification changes over time in response to shocks to firm specific characteristics (ability, productivity, competences) and to product specific attributes (technology, demand for product characteristics), with the latter possibly idiosyncratic also across destinations. Although the role of financial constraints is not explicitly considered, simple economic intuition suggests that financing constraints, just as other firms' attributes, can be important since negative shocks to firms' financial status makes them more vulnerable. However, the relationship with the probability of dropping products or destinations is a priori ambiguous and depends on the nature of the constraints. If financial constraints are binding only with respect to the country- or product-specific fixed costs of exporting, we could expect that constrained firms make the effort to stay in the market in the attempt to recover such costs. This would imply a negative correlation between financial status and the probability of dropping products or destinations. But if, in addition, external finance is needed to also cover recurrent costs of exporting, such as transportation costs or the costs of maintaining foreign distribution networks, then financial constraints could reduce the ability of firms to stay in the market, directly increasing the probability of dropping products and countries. ${ }^{18}$

We start by studying product dropping choices. We define an indicator variable at the firm-product level, $\operatorname{Drop} P_{f p, t}$, that takes value 1 if product $p$ is exported by firm $f$ at time $t-1$, but not exported

\footnotetext{
${ }^{18}$ Askenazy et al. (2011) formalizes this intuition in a model where financial frictions hamper a firm ability to finance the recurrent costs and decrease its survival in a foreign country. The model however does not explicit consider the dropping choices of multi-product firms.
} 
Table 4: FINANCIAL CONSTRAINTS AND PRODUCT/DESTINATION DROPPING

\begin{tabular}{|c|c|c|c|c|c|c|c|c|}
\hline \multirow[t]{3}{*}{ Dependent variable } & \multicolumn{4}{|c|}{$\operatorname{Drop}_{f p, t}$} & \multicolumn{4}{|c|}{$\operatorname{Drop}_{f c, t}$} \\
\hline & (1) & $(2)$ & (3) & (4) & (5) & $(6)$ & $(7)$ & $(8)$ \\
\hline & Probit & FE & $\begin{array}{c}\text { FE } \\
\text { No marginal } \\
\text { products }\end{array}$ & $\begin{array}{c}\text { FE } \\
\text { Selection }\end{array}$ & Probit & $\mathrm{FE}$ & $\begin{array}{c}\mathrm{FE} \\
\text { No marginal } \\
\text { countries }\end{array}$ & $\begin{array}{c}\text { FE } \\
\text { Selection }\end{array}$ \\
\hline $\ln F C_{f, t-1}$ & $\begin{array}{c}0.028^{* * * *} \\
(0.006)\end{array}$ & $\begin{array}{c}0.016^{* * *} \\
(0.006)\end{array}$ & $\begin{array}{c}0.017 * * \\
(0.007)\end{array}$ & $\begin{array}{c}0.033^{* * * *} \\
(0.005)\end{array}$ & $\begin{array}{c}0.028 * * * \\
(0.004)\end{array}$ & $\begin{array}{c}0.014 * * * \\
(0.005)\end{array}$ & $\begin{array}{c}0.019 * * * \\
(0.005)\end{array}$ & $\begin{array}{c}0.033^{* * * *} \\
(0.004)\end{array}$ \\
\hline $\ln T F P_{f, t-1}$ & $\begin{array}{c}-0.010 * * * \\
(0.003)\end{array}$ & $\begin{array}{c}0.002 \\
(0.005)\end{array}$ & $\begin{array}{c}-0.011^{* *} \\
(0.004)\end{array}$ & $\begin{array}{c}-0.021 * * * \\
(0.003)\end{array}$ & $\begin{array}{c}-0.005^{* *} \\
(0.002)\end{array}$ & $\begin{array}{c}-0.007 * * \\
(0.003)\end{array}$ & $\begin{array}{c}-0.015^{* * *} * \\
(0.004)\end{array}$ & $\begin{array}{c}-0.030 * * * \\
(0.002)\end{array}$ \\
\hline $\ln E m p l_{f, t-1}$ & $\begin{array}{c}-0.008 * * * \\
(0.002)\end{array}$ & $\begin{array}{l}0.008^{*} \\
(0.005)\end{array}$ & $\begin{array}{c}-0.016 * * * \\
(0.005)\end{array}$ & $\begin{array}{c}-0.045^{* * *} * \\
(0.003)\end{array}$ & $\begin{array}{c}-0.017 * * * \\
(0.001)\end{array}$ & $\begin{array}{c}-0.014 * * * \\
(0.004)\end{array}$ & $\begin{array}{c}-0.024 * * * \\
(0.004)\end{array}$ & $\begin{array}{c}-0.066 * * * \\
(0.003)\end{array}$ \\
\hline $\ln A g e_{f, t-1}$ & $\begin{array}{l}-0.003 \\
(0.002)\end{array}$ & $\begin{array}{c}0.100 * * * \\
(0.015\end{array}$ & $\begin{array}{c}0.058 * * * \\
(0.017)\end{array}$ & $\begin{array}{c}0.199 * * * \\
(0.013)\end{array}$ & $\begin{array}{c}0.004 * * * \\
(0.001)\end{array}$ & $\begin{array}{c}0.101 * * * \\
(0.012)\end{array}$ & $\begin{array}{c}0.070 * * * \\
(0.013)\end{array}$ & $\begin{array}{c}0.080 * * * \\
(0.009)\end{array}$ \\
\hline $\ln$ Assets $_{f, t-1}$ & $\begin{array}{c}-0.010 * * * \\
(0.002)\end{array}$ & $\begin{array}{c}-0.028 * * * \\
(0.006)\end{array}$ & $\begin{array}{c}-0.047 * * * \\
(0.006)\end{array}$ & $\begin{array}{c}-0.090 * * * \\
(0.004)\end{array}$ & $\begin{array}{c}-0.011 * * * \\
(0.001)\end{array}$ & $\begin{array}{c}-0.039 * * * \\
(0.005)\end{array}$ & $\begin{array}{c}-0.043 * * * \\
(0.005)\end{array}$ & $\begin{array}{c}-0.075 * * * \\
(0.004)\end{array}$ \\
\hline $\ln G O M_{f, t-1}$ & $\begin{array}{c}-0.003 * * * \\
(0.001)\end{array}$ & $\begin{array}{r}-0.0004 \\
(0.001)\end{array}$ & $\begin{array}{l}0.0003 \\
(0.001)\end{array}$ & $\begin{array}{c}0.001 * * * \\
(0.0001)\end{array}$ & $\begin{array}{c}-0.008 * * * \\
(0.0005)\end{array}$ & $\begin{array}{l}-0.0005 \\
(0.0007)\end{array}$ & $\begin{array}{c}0.0004 \\
(0.0007)\end{array}$ & $\begin{array}{c}0.002 * * * \\
(0.0004)\end{array}$ \\
\hline Year FE & Yes & Yes & Yes & Yes & Yes & Yes & Yes & Yes \\
\hline Firm FE & No & Yes & Yes & Yes & No & Yes & Yes & Yes \\
\hline Product FE & No & Yes & Yes & No & No & No & No & No \\
\hline Country FE & No & No & No & No & No & Yes & Yes & Yes \\
\hline Adj. $\mathrm{R}^{2}$ & 0.009 & 0.152 & 0.345 & 0.560 & 0.018 & 0.188 & 0.301 & 0.573 \\
\hline N.Observations & $1,031,616$ & $1,031,616$ & 401,400 & $9,871,750$ & $1,158,554$ & $1,158,554$ & 600,190 & $16,890,120$ \\
\hline
\end{tabular}

Note: Regression using data on 2001-2003, for firms exporting at least one product in both $t-1$ and $t$ (Surviving firms). All the regressions include a constant term. Robust standard errors in parenthesis, clustered at firm level. The standard errors for the coefficients in columns 4 and 8 are computed out of 200 bootstrap runs (see the Technical Appendix for details). Asterisks denote significance levels $(* * *: p<1 \%$; **: p $<5 \%$; $:$ p $<10 \%)$. Mc Fadden's Pseudo $R^{2}$ reported in columns 1 and 5 .

by the same firm in year $t$. We then estimate the equation

$$
\operatorname{Drop}_{f p, t}=\alpha+\gamma F C_{f, t-1}+\boldsymbol{\beta} \mathbf{Z}_{f, t-1}+\mu_{f}+\mu_{p}+\epsilon_{f p, t}
$$

where $\mathbf{Z}_{f}$ is the usual set of lagged firm-level controls, while $\mu_{f}$ and $\mu_{p}$ are firm and product fixed effects accounting for time invariant unobserved characteristics that may influence the decision to drop a product. Accordingly, the coefficient of main interest, $\gamma$, is identified through variation of FC status idiosyncratic to individual firm-product pairs, over time. The analysis only considers firms which do not drop all their products in two consecutive years (surviving firms). This avoids confounding factors related to the likely different motivation behind the choice to completely exit from export markets. Results are therefore informative on dropping conditional on survival in export markets between two consecutive years.

Columns 1-2 of Table 4 present baseline estimates. In columns 1 we report for reference the marginal effects (at the sample average of regressors) from a simple Probit regression, where we ignore fixed effects due to standard incidental parameter problem. In column 2, we show the estimates of a linear probability model with firm and product fixed effects. This estimation strategy suffers from predicted probabilities outside the $[0,1]$ range, but it provides a stronger identification controlling for a broad set of unobserved factors. Results are quite robust. Both specifications identify a positive and significant coefficient. Taking the more accurate estimates with firm-and-product fixed effects, the FC coefficient is 0.016 . Given an average drop rate of $42.3 \%$ among unconstrained firms, this means that a within-firm change in the FC dummy over time entails a $3.8 \%$ higher probability of dropping a product, in the same product market. 
In column 3 and 4 we perform two robustness checks. In column 3 we address potential withinfirm portfolio composition effects along the dropping dynamics. Existing studies indicate that multiproduct firms are less likely to drop core products that account for a large share in their export value (Bernard et al., 2010; de Nardis and Pappalardo, 2009). If constrained firms have a higher propensity to drop fringe products, a bias in $\gamma$ might come from an uncontrolled relationship between FC status and number of marginal products. Accordingly, we re-estimate the linear probability model with fixed effects after excluding the observations on marginal products, defined as those involving less than $1 \%$ of the total exports of each firm. The estimated coefficient on the FC dummy remains positive and significant, with magnitude comparable to the whole-sample result in column 2. Finally, in column 4 , we control for potential selection bias arising from the fact that we observe the dependent variable only for those products that are actually exported by each firm. We employ a methodology similar to that adopted in the previous section. In this case, however, the firm-product level information allows to model selection into export as the outcome of a Tobit regression. The results confirm the evidence of a positive and significant correlation between a firm's FC status and the probability of dropping a product. $^{19}$

Next, we perform a similar set of regressions focusing on destination dropping probabilities. We define an indicator of destination dropping, $\operatorname{Drop} C_{f c t}$, that equals 1 if country $c$ is served by firm $f$ at time $t-1$, but not served in year $t$. The baseline regression equation becomes

$$
\operatorname{Drop}_{f c, t}=\delta F C_{f, t-1}+\boldsymbol{\beta} \mathbf{Z}_{f, t-1}+\mu_{f}+\mu_{c}+\epsilon_{f c t}
$$

where we include firm $\left(\mu_{f}\right)$ and country $\left(\mu_{c}\right)$ fixed effects. As before, the analysis only considers surviving firms.

Results are reported in the left panel of Table 4. Column 5 shows Probit marginal effects (at regressors sample averages), while column 6 shows the coefficients of the linear probability regression with firm and destination fixed effects. Results are quite similar to those observed for product dropping. The only important difference concerns the magnitude of the correlation between FCs and destination dropping. Indeed, despite the point estimates of $\gamma(0.014$ from FE model) are basically identical, financial constraints increase the probability of dropping a destination of 6.4 percentage points, twice as big as the magnitude observed for product-dropping (the average country dropping rate is $21.9 \%$ ). These findings remain robust when we exclude irrelevant destinations (those involving less than $1 \%$ of total exports) and when we control for selection with the Semykina and Wooldridge (2010) procedure with Tobit selection (see Technical Appendix). The estimate of $\gamma$ in our favorite specification (column 8) implies that a within-firm change in FC status over time entails, on average, a $15.1 \%$ higher probability of dropping a destination confirming a much stronger correlation of FCs with dropping destinations, as compared to dropping products.

Altogether, our findings about dropping dynamics support the economic intuition that access to

\footnotetext{
${ }^{19}$ The coefficient is, however, doubled as compared to baseline FE regression in column 2 . This is likely due to the fact that in this specification we cannot control for product fixed effects since our dataset does not have time varying product characteristics. See the Technical Appendix for further details on the estimation procedure. The advantage of using a Tobit in the selection equation is that there is no need of an exclusion restriction since the variation in the dependent variable can be used to identify the parameters in the main equation.
} 


\begin{tabular}{|c|c|c|c|c|c|c|}
\hline \multirow[t]{4}{*}{ Dependent variable } & \multicolumn{3}{|c|}{ Share PDropped $_{f, t}$} & \multicolumn{3}{|c|}{ Share $_{\text {CDropped }}$ Drtt } \\
\hline & (1) & $(2)$ & (3) & (4) & $(5)$ & (6) \\
\hline & FE & $\mathrm{FE}$ & FP & FE & FE & FP \\
\hline & & $\begin{array}{c}\text { No marginal } \\
\text { products }\end{array}$ & Selection & & $\begin{array}{c}\text { No marginal } \\
\text { countries }\end{array}$ & Selection \\
\hline \multirow[t]{2}{*}{$F C_{f, t-1}$} & $0.036 * * *$ & $0.042 * * *$ & $0.030 * * *$ & $0.030 * * *$ & $0.031 * *$ & $0.017 * * *$ \\
\hline & $(0.010)$ & $(0.014)$ & $(0.006)$ & $(0.011)$ & $(0.016)$ & $(0.005)$ \\
\hline \multirow{2}{*}{$\ln T F P_{f, t-1}$} & $-0.022 * * *$ & $-0.022 * *$ & $-0.010 * *$ & $-0.034 * * *$ & $-0.034 * * *$ & $-0.015^{* *}$ \\
\hline & $(0.007)$ & $(0.010)$ & $(0.004)$ & $(0.007)$ & $(0.011)$ & $(0.004)$ \\
\hline \multirow{2}{*}{$\ln E m p l_{f, t-1}$} & $-0.035 * * *$ & $-0.038 * * *$ & $-0.024 * * *$ & $-0.043 * * *$ & $-0.047 * * *$ & $-0.024 * * *$ \\
\hline & $(0.007)$ & $(0.010)$ & $(0.004)$ & $(0.008)$ & $(0.012)$ & $(0.004)$ \\
\hline \multirow{2}{*}{$\ln A g e_{f, t}$} & $-0.064 * *$ & $-0.092 * *$ & -0.020 & $-0.066^{* *}$ & $-0.123 * * *$ & -0.007 \\
\hline & $(0.026)$ & $(0.039)$ & $(0.016)$ & $(0.028)$ & $(0.045)$ & $(0.015)$ \\
\hline \multirow[t]{2}{*}{$\ln \operatorname{Assets}_{f, t-1}$} & $-0.052 * * *$ & $-0.058 * * *$ & $-0.047 * * *$ & $-0.042 * * *$ & $-0.041 * * *$ & $-0.033 * * *$ \\
\hline & $(0.009)$ & $(0.013)$ & $(0.006)$ & $(0.010)$ & $(0.016)$ & $(0.005)$ \\
\hline \multirow[t]{2}{*}{$\ln G O M_{f, t-1}$} & 0.002 & 0.002 & 0.001 & $0.003 * *$ & 0.002 & 0.0001 \\
\hline & $(0.001)$ & $(0.002)$ & $(0.001)$ & $(0.001)$ & $(0.003)$ & $(0.001)$ \\
\hline \multirow[t]{2}{*}{ \#Products dropped ${ }_{f, t-1}$} & $0.007 * * *$ & $0.047 * * *$ & $0.013 * * *$ & & & \\
\hline & $(0.001)$ & $(0.001)$ & $0.001)$ & & & \\
\hline \#Countries dropped $d_{f, t-1}$ & & & & $\begin{array}{c}0.017 * * * \\
(0.001)\end{array}$ & $\begin{array}{c}0.066 * * * \\
(0.002)\end{array}$ & $\begin{array}{c}0.031 * * * \\
(0.001)\end{array}$ \\
\hline Year FE & Yes & Yes & Yes & Yes & Yes & Yes \\
\hline Firm FE & Yes & Yes & Yes & Yes & Yes & Yes \\
\hline Adj. $\mathrm{R}^{2}$ & 0.734 & 0.684 & - & 0.702 & 0.652 & - \\
\hline N.Observations & 72,369 & 49,873 & 86,200 & 65,886 & 43,015 & 86,200 \\
\hline
\end{tabular}

Note: Regression using data on 2001-2003, for firms that export at least one product in both $t-1$ and $t$ (Surviving firms). Regressions in columns 1-2 and 4-5 include only firms that dropped products or countries, while those in columns 3 and 6 consider also firms that did not drop (i.e. zeros of the dependent variable are included) and are estimated via fractional probit (FP) model (Papke and Wooldridge, 2008). In column 2 and column 5 regressions only include observations on core products and of core countries dropped. All the regressions include a constant term. Robust standard errors in parenthesis, clustered at firm level. Asterisks denote significance levels (***:p $<1 \%$; **: $\mathrm{p}<5 \%$; $: \mathrm{p}<10 \%)$.

external finance matters to finance both the fixed and variable costs required to keep exporting a product and serving a destination. A qualification of this general result is that, if we look within the same firm, then becoming FC over time has a stronger correlation with the probability to stop serving a country than with the likelihood to withdraw a product from the export bundle.

\section{Shares of foreign sales from dropped products and countries}

We know, from the distributional comparisons in Section 3, that to-be-dropped products and countries represent a relevant share in firm foreign sales, and that the magnitude of this intra-firm adjustment varies across firms with different access to external financing. Here we check whether financial constraints, through their influence on product/destination dropping, can also play a detrimental role on total firm revenues from foreign sales. The theory and previous empirical studies are silent on this point. 
We estimate the following baseline regressions

Share PDropped Dr,t $=\alpha+\gamma F C_{f, t-1}+\boldsymbol{\beta Z}_{f, t-1}+$ \#Products dropped $_{f, t-1}+\mu_{f}+\epsilon_{f, t}$,

Share C Dropped Dr,t $=\alpha+\gamma F C_{f, t-1}+\boldsymbol{\beta Z}_{f, t-1}+\#$ Countries dropped $_{f, t-1}+\mu_{f}+\epsilon_{f, t}$,

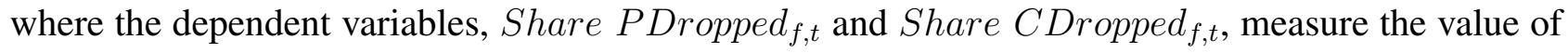
export transactions associated with products or destinations dropped by firm $f$ between $t-1$ and $t$, as a share of total firm exports in the initial year. In these two regressions we need to take into account the fact that constrained firms are more likely to drop products or destinations. Thus, in addition to usual firm-level controls, $\mathbf{Z}$, we also include the number of products or the number of countries dropped by the firm from $t-1$ to $t$, respectively labeled \#Products dropped and \#Countries dropped. Given the inclusion of firm fixed effects $\left(\mu_{f}\right)$, our main coefficient of interest $\gamma$ is identified trough variation of FC status within firm over time.

Column 1 of Table 5 presents the baseline FE estimates for equation 7. They yield a positive and statistically significant FC dummy coefficient. Given an average share of exports associated with dropped products of $19 \%$ among unconstrained firms, the point estimate (0.036) implies that a within firm change in the financial status over time associates, on average, with an $19 \%$ increase in the share of to-be-dropped products in overall firm exports. In column 2 we re-estimate the regression on the sub-sample of core products, to get rid of confounding factors behind firms' choices on marginal goods. Results are fully preserved. In column 3 we tackle selection bias potentially arising from the fact that there might be firms that do not drop at all between two consecutive years, and thus have a zero share of to be dropped products. To clean this potential selection bias we include in the sample zero share observations and estimate a fractional Probit panel data model (Papke and Wooldridge, 2008). The results corroborate the conclusion that firms becoming constrained over time have a significantly higher share of foreign sales from to-be-dropped products than unconstrained firms.

In Columns 4-6 of the same Table 5 we present the estimates of the regression on the export shares associated to country dropping. The results fit well with the picture emerged from the product dropping analysis. We still observe a positive coefficient on the FC dummy, even when excluding transactions involving marginal countries (column 5) and when accounting for possible selection bias due to zero shares attached to firms that do not drop countries (again via fractional Probit, in column 6). Taking the result from the baseline FE regression, the point estimate of $\gamma$ is 0.031 representing a $21.9 \%$ increase in the share of foreign sales associated to to-be-dropped destinations (the average share of exports associated with to-be-dropped countries is $14.1 \%$ ).

Concluding, our evidence supports the idea that the detrimental role of financial constraints goes beyond their association with an increased probability to exit from product or country markets. A distinguishing feature of constrained firms is also that they loose more export value than unconstrained firms from such more frequent dropping. The next section concludes the analysis exploring whether the weaker performance of constrained firms along the dropping dynamics presents any peculiar relationship with product and country specific characteristics. 

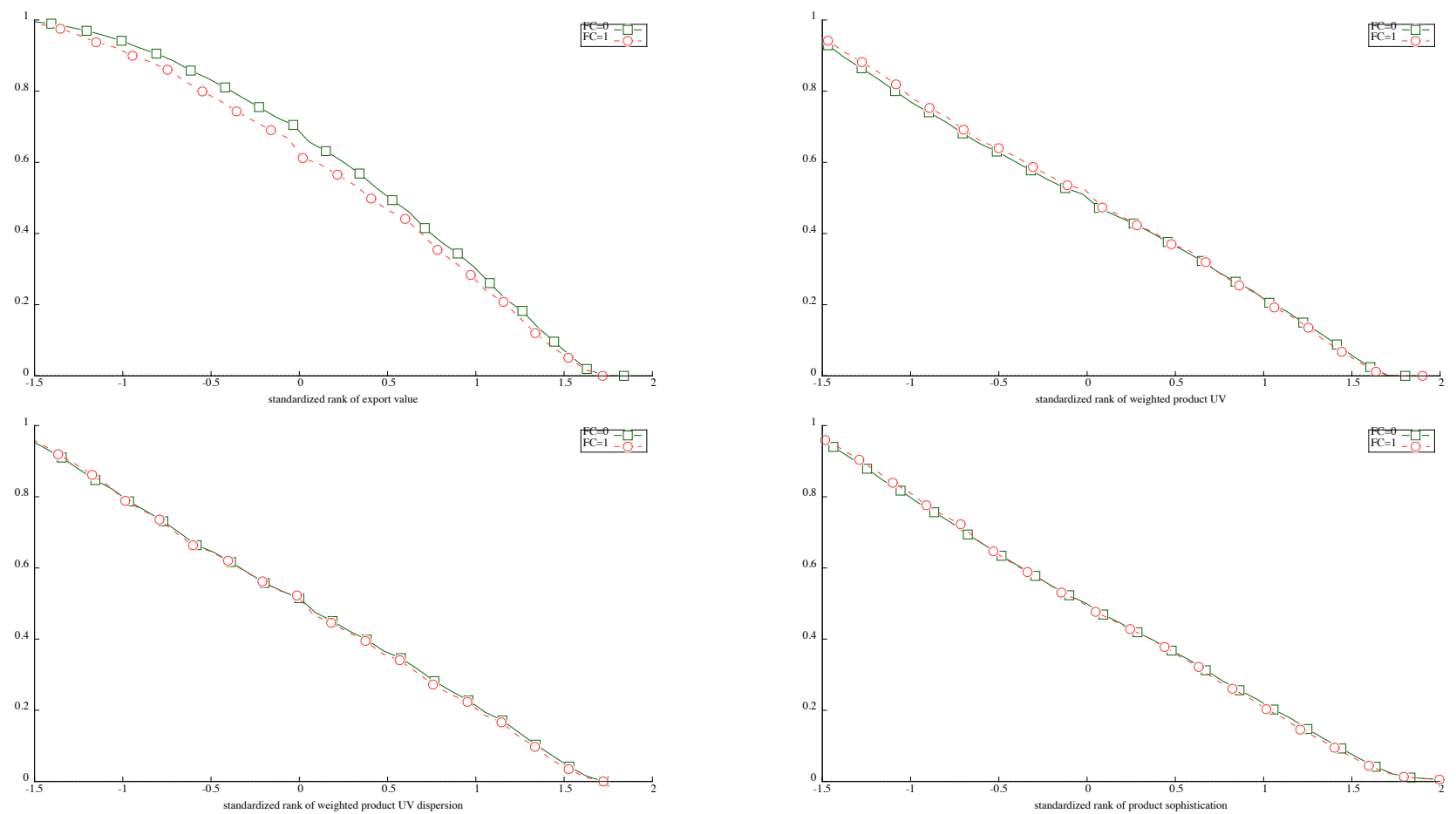

Figure 2: COMPLEMENTARY CUMULATIVE DISTRIBUTION FUNCTIONS (CCDF) OF PRODUCT ATTRIBUTES BY FINANCIAL CONSTRAINTS STATUS - YEAR 2003.

Notes: CCDF by unconstrained (thin line) vs. constrained firms (thick line) of standardized rank of export values (Topleft), weighted product unit values (top-right), weighted product unit values dispersion (bottom-left), and product sophistication (bottom-right).

\section{What do constrained firms drop ?}

The characteristics of products and destinations are likely to represent important determinants of the choice to drop them. Bernard et al. (2010), for instance, suggest that products with lower turnover and shorter tenure are more likely to be dismissed. In this section we provide a qualitative investigation to understand whether FC firms display specific peculiarities with respect to the type of products and markets they choose to drop. Addressing this issue points at a more detailed characterization of the detrimental effect of financial constraints, potentially revealing some deeper factors underlying the observed dropping decisions.

We proceed as follows. First, we identify a set of product and destination attributes which capture some of the factors that the micro-trade literature suggests as relevant for the ability of firms to start and sustain exporting. Then, we compare the distributions of these attributes across export transactions dropped by FC and NFC firms.

\section{Characteristics of dropped products}

We focus on four different product attributes. Two are the standard attributes related to the core products concept of multi-product firms. First, we employ a product's export share in total export value as a proxy for its relative importance within a firm export bundle. Second, we use the unit value charged by a firm for a given product as a measure of either its intrinsic quality, or of the unit 
margin extracted by a firm from that specific product. ${ }^{20}$ Further, we look at two different aspects of product homogeneity: the coefficient of variation of product unit values across a firm transactions involving that product (Bernard et al., 2013), and the degree of product sophistication as measured by the PRODY index (Hausmann et al., 2007). ${ }^{21}$

For each attribute we define a standardized ranking index

$$
R(W)_{p f}=\frac{\operatorname{rank}(\mathrm{W})_{p f}-\operatorname{Avg} \cdot \operatorname{rank}(\mathrm{W})_{f}}{S t d \cdot \operatorname{Dev} \cdot \operatorname{rank}(\mathrm{W})_{f}}
$$

where $\operatorname{rank}(\mathrm{W})_{p f}$ indicates how product $p$ ranks in the distribution of the attribute $W$ computed across all the export transactions of firm $f$ at time $t$. Avg. and Std.Dev. denote average and standard deviation of the same within firm and across products distribution of the attribute. The desirable property of the index is that it is firm specific (i.e. it looks at within firm rankings, controlling for the total number of products a firm exports), thus allowing for meaningful comparisons of rankings across firms. Given the standardization, a positive value of $R(W)$ indicates that product $p$ ranks higher in terms of attribute $W$ than the average ranking of all the other products of the firm. Hence, a positive value of $R(W)$ identifies those products, in a firm's portfolio, that are less important with respect to that attribute. Symmetrically, a negative value of the index refers to products that are more important for the firm with respect to attribute $W$.

Figure 2 reports, for each product attribute, the CCDF of the $R(W)$ indexes of those products dropped by a firm between $t-1$ and $t$. The plots report the distribution of FC (thick line) and NFC firms (thin line) in 2003 (comparable estimates in the other years). We find evidence of two main patterns. First, irrespective of the FC status, we observe a concave CCDF when we focus on the rank in terms of export share (cfr. top left plot), while an almost linear CCDF when we look at the other three attributes. This suggests that all firms, in general, tend to drop more their relatively marginal products, while there is no evidence of any asymmetric pattern regarding top vs. low rankings in unit values, unit values dispersion or product sophistication. Second, by looking closely at the rankings of export value (top-left plot), we observe that the CCDF of NFC firms dominates that of FC firms. This means that financially constrained firms are likely to drop relatively more frequently than unconstrained firms those products that are closer to the within firm products core. Conversely, we do not observe significant differences between FC and NFC concerning other attributes, which indeed overlap over the entire support. The conclusions from graphical analysis are confirmed by the Fligner-Policello test of stochastic dominance whose results are reported in Table 6. 


\begin{tabular}{llcc}
\hline \multicolumn{2}{c}{ Product } & Test statistics & P-value \\
\hline & & & \\
& Standardized rank of export share & -10.94 & $<0.0001$ \\
& standardized rank of weighted UV & 1.93 & 0.05 \\
& standardized rank of weighted UV dispersion & -1.52 & 0.128 \\
& standardized rank of product sophistication & -0.19 & 0.846 \\
\hline \multirow{4}{*}{ Country } & & & \\
& & & \\
& standardized rank of export share & -23.81 & $<0.0001$ \\
& standardized rank of gdp & -13.32 & $<0.0001$ \\
& standardized rank of gdp per capita & -12.71 & $<0.0001$ \\
& standardized rank of distance & 5.60 & $<0.0001$ \\
\hline
\end{tabular}

Notes: Fligner and Policello (1981) test of stochastic dominance.

\section{Characteristics of dropped countries}

We then perform a similar analysis for a set of country-specific attributes. We again look at the position of destinations in terms of the associated shares in total firm exports. Further, we focus on a set of gravity factors, that are well know to play a role in shaping firms' trade activities. These are market size, consumer income, and iceberg trade costs, which we measure in a standard way by GDP, GDP per capita (GDPPC) and bilateral geographical distance (DIST). ${ }^{22}$

For each attribute we compute the corresponding standardized ranking index $R(W)$ following equation 9. We then plot the distribution of the indexes of the dropped destinations, comparing the pattern of FC and NFC firms. We show the results for 2003. Figure 3 presents the CCDFs of $R(W)$ for the four attributes, while Table 6 reports the associated FP-test of stochastic dominance between the two groups of NFC and FC firms.

First, looking at rankings in terms of export value (Figure 3, top-left plot), we observe that all firms, irrespective of the FC status, drop comparatively more those destinations with rankings above the within-firm average. That is, there is a general tendency to drop more frequently marginal markets, in agreement with the results from product attributes. However, we observe that constrained firms are more likely than unconstrained ones to discard also some relevant destinations. This is suggested by the clear separation between the estimated CCDFs and confirmed by the stochastic dominance of the NFC firms distribution over the FC firms distribution (cfr. Table 6). Second, concerning both GDP and GDP per-capita, we observe that FC and NFC firms, in general, drop less frequently the

\footnotetext{
${ }^{20}$ To obtain a unit value associated to each product $p$, following Manova and Zhang (2012a), we take the weighted average of the unit values charged by firm $i$ for product $p$ across all the destinations wherein the firm exports the product, using as weights the share of each destination in the total export revenues from exporting a given product.

${ }^{21}$ We follow Di Maio and Tamagni (2008) who provide a "dynamic" version of the original PRODY index, computed following evolution of export sophistication in the 777 2-digit product categories of the SIC Rev.2 classification over the period 1980-2000. These are matched with our HS6-1996 product categories. We take values of the indexes as of the year 2000 .

${ }^{22}$ Data on GDP and GDP per capita are taken from the World Bank Development Indicators (nominal figures). Computation of distance from Italy follows the great circle method (Mayer and Zignago, 2005) from the CEPII database.
} 

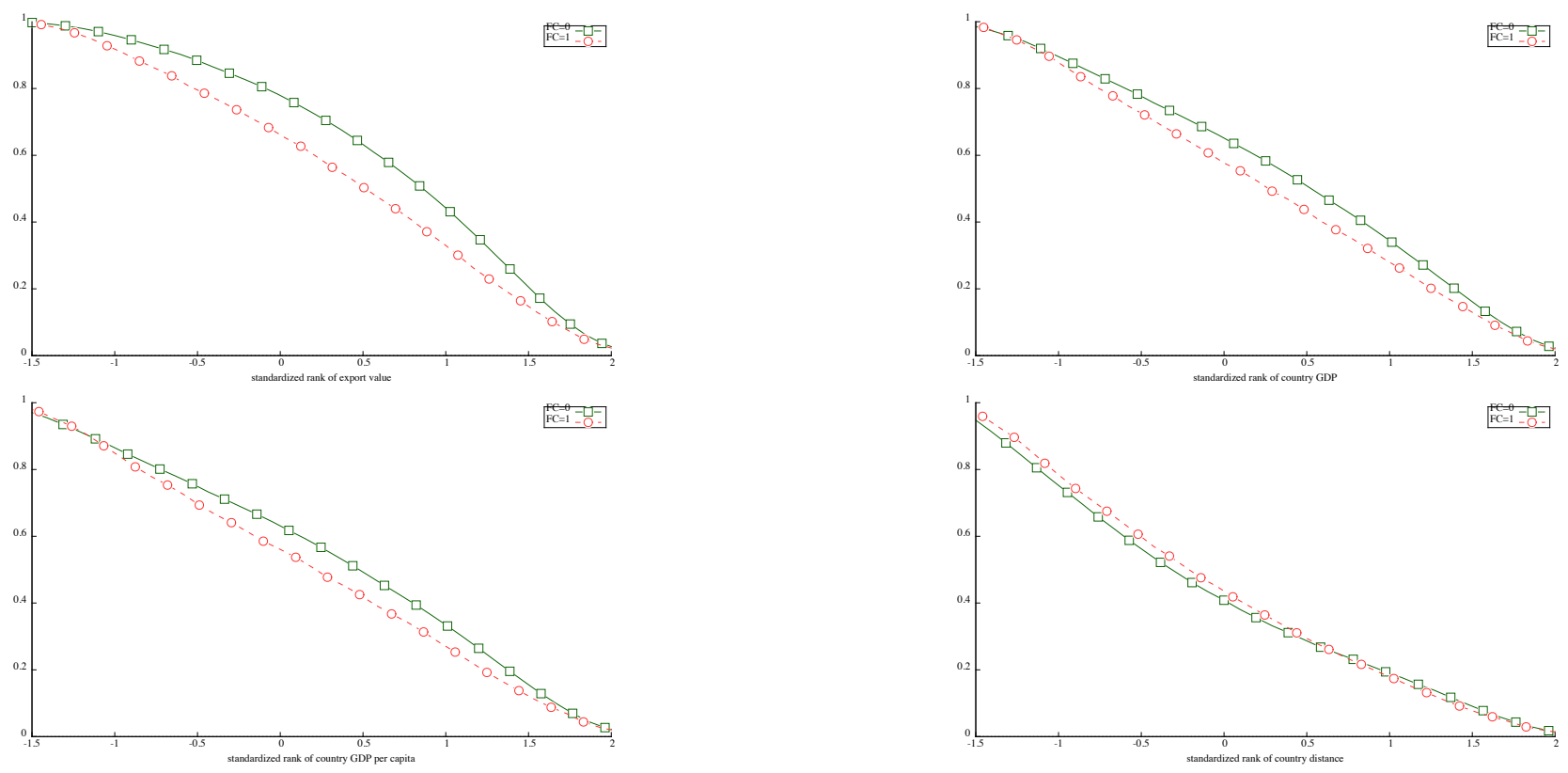

Figure 3: COMPLEMENTARY CUMULATIVE DISTRIBUTION FUNCTIONS (CCDF) OF COUNTRY ATTRIBUTES BY FINANCIAL CONSTRAINTS STATUS - YEAR 2003.

Notes: CCDF by unconstrained (thin line) vs. constrained (thick line) firms of standardized rank of export values (topleft), country GDP (top-right), country GDP per capita (bottom-left), and country distance (bottom-right).

comparatively richer and bigger countries of their export portfolio. However, NFC firms are more successful than FC firms in maintaining their presence in this type of markets. Indeed, the CCDFs of GDP and GDPPC estimated for the transactions dropped by FC firms are less concave than the corresponding CCDF estimated for the transactions dropped by NFC firms. FP tests confirm that the NFC distribution dominates the FC distribution. Finally, concerning geographical distance, the general result is that all firms, irrespective of FC status, drop more frequently destinations that are more far away from Italy. However, it is the distribution of transactions dropped by FC firms that dominates in this case, as revealed by the positive sign of the FP test statistics. This means that constrained firms drop more those destinations with that are relatively closer to Italy as compared to other destinations served by the firm.

Overall, our results are quite informative. First, we qualify the above regression results that dropped products and destinations have a comparatively higher share in total exports of constrained firms. Indeed, we reveal that these results come from discarding both marginal and relatively more core products and destinations. Second, a further peculiarity of constrained firms is their relatively weaker ability to remain active in destination countries which, within their portfolios, are larger and richer. To the extent that the presence in bigger and richer markets provides opportunities to sustain overall firm value, this result signals a further channel trough which constraints can influence overall export performance. Third, we observe that constrained exporters drop more frequently than unconstrained firms also those destinations which are at relatively lower distance within their export portfolio. ${ }^{23}$ This appears puzzling. A possible interpretation is related to the fact that countries closer

\footnotetext{
${ }^{23} \mathrm{~A}$ comparison between NFC and FC firms across destinations reveals that this result is not merely due to a disproportionate presence of FC firms in geographical areas closer to Italy.
} 
to Italy are those where competition tends to be fiercer. Since constrained firms are more vulnerable than their unconstrained competitors, then they might be more likely to drop precisely these closer and more competitive destinations. This appears also in line with the results obtained for GDP and GDPPC rankings.

\section{Conclusion}

The present paper examines the potential role of financial constraints in affecting product and geographical diversification of exporting firms. We use detailed firm-product-destination data on the international activities of a sample of firms covering the vast majority of Italian exports. Exploiting the information on firm-level financial constraints measured via credit ratings, we contribute to the relatively underdeveloped literature in a number of directions.

First, when we look at the extent of diversification, we document that financial constraints associate with serving fewer countries and shipping a narrower range of products, both across and within firms. Such reduced activity, already observed in previous studies, hints at the existence of relevant country-specific and product-specific fixed costs.

Second, by looking at the over time variation within firm and product or within firm and destination, we shed light on the process of discarding products or destinations which underlies the changes in the overall scope of diversification of firms. We observe that constraints significantly increase the probability to drop both products and destinations. Moreover, the choices of dropping entail a considerable amount of reallocation of resources within the firm. Indeed, for constrained firms, the share in total export value of the transactions associated to discarded products and destinations is sizable, and bigger as compared to what observed for unconstrained firms. Our estimates, in particular, signal that constrained firms are more resilient to discard products than to discard destinations, suggesting that financing problems are more relevant for the decision to remain in a destination market than for the choice to withdraw products from the export bundle. These findings highlight the relevance of differential access to credit as a new crucial determinant which models of within-firm churning by multi-product, multi-destination firms have not yet considered.

Finally, we explore whether there is a systematic relationship between firm level credit conditions and product- or destination-specific attributes of the products or countries dropped by firms. The findings hint at the potential channels trough which financial constraints can adversely affect overall export performance via their impact on dropping dynamics. The general result is that dropping decisions of constrained firms respond more to destination characteristics than to product attributes. However, we also observe peculiar behavior along some specific attributes, for which we can only advance tentative interpretations, open to further research. The comparatively weaker ability of constrained firms to preserve more core products and destinations is a signal that constraints do distort the diversification choices of firms, forcing them to also discard some non-marginal and profitable products and country markets. Further, their difficulty to remain active in comparatively richer, bigger and closer countries represent a signals that constraints may work trough undermining the ability to respond to competition, technology or quality related challenges. 


\section{References}

Ahn, J., A. K. Khandelwal, And S.-J. WeI (2011): "The role of intermediaries in facilitating trade," Journal of International Economics, 84, 73-85.

Albornoz, F., H. F. Calvo Pardo, G. Corcos, and E. Ornelas (2012): "Sequential exporting," Journal of International Economics, 88, 17-31.

Askenazy, P., A. Caldera, G. Gaulier, And D. IraC (2011): "Financial Constraints and Foreign Market Entries or Exits: Firm-Level Evidence from France," Working papers 328, Banque de France.

Bellone, F., P. Musso, L. Nesta, And S. Schiavo (2010): "Financial Constraints and Firm Export Behaviour," The World Economy, 33, 347-373.

BERMAN, N. AND J. HRICOURT (2010): "Financial factors and the margins of trade: Evidence from cross-country firm-level data," Journal of Development Economics, 93, 206-217.

Bernard, A. B., M. Grazzi, And C. TOMASi (2013): "Intermediaries in international trade: margins of trade and export flows," Tech. rep., University of Trento, mimeo.

Bernard, A. B. And J. B. Jensen (2004): "Why Some Firms Export," The Review of Economics and Statistics, 86, 561-569.

Bernard, A. B., J. B. Jensen, S. J. Redding, And P. K. Schott (2007): "Firms in International Trade," Journal of Economic Perspectives, 21, 105-130.

Bernard, A. B., S. J. Redding, And P. K. Schott (2010): "Multiple-Product Firms and Product Switching," American Economic Review, 100, 70-97.

(2011): "Multi-Product Firms and Trade Liberalization," Quarterly Journal of Economics, forthcoming.

Bottazzi, G., A. Secchi, And F. TAmagni (2008): "Productivity, profitability and financial performance," Industrial and Corporate Change, 17, 711-751.

— (2014): "Financial constraints and firm dynamics," Small Business Economics, 42, 99-116.

Chaney, T. (2008): "Distorted Gravity: The Intensive and Extensive Margins of International Trade," American Economic Review, 98, 1707-21.

Chatterjee, A., R. Dix-Carneiro, and J. Vichyanond (2013): "Multi-product Firms and Exchange Rate Fluctuations," American Economic Journal: Economic Policy, 5, 77-110.

De Nardis, S. And C. Pappalardo (2009): "Export, Productivity and Product Switching: The Case of Italian Manufacturing Firms," ISAE Working Papers 110, ISTAT - Italian National Institute of Statistics - (Rome, ITALY). 
Di Maio, M. And F. TAmagni (2008): “The Evolution of World Export Sophistication and the Italian Trade Anomaly," Rivista di Politica Economica, 98, 135-174.

Eckel, C., L. Iacovone, B. Javorcik, And J. P. NeARy (2011): "Multi-Product Firms at Home and Away: Cost- versus Quality-based Competence," CEPR Discussion Papers 8186, C.E.P.R. Discussion Papers.

FARre-Mensa, J. AND A. LJUngQVist (2013): “Do measures of Financial Constraints Measure Financial Constraints?” NBER Working Paper 19551, National Bureau of Economic Research.

Fligner, M. A. And G. E. Policello (1981): "Robust rank procedures for the Behrens-Fisher problem," Journal of the American Statistical Association, 76, 141-206.

Goldberg, P. K., A. K. Khandelwal, N. Pavcnik, and P. Topalova (2010): "Multiproduct Firms and Product Turnover in the Developing World: Evidence from India," The Review of Economics and Statistics, 92, 1042-1049.

Greenaway, D., A. Guariglia, And R. Kneller (2007): "Financial factors and exporting decisions," Journal of International Economics, 73, 377-395.

Guiso, L., L. Pistaferri, And F. Schivardi (2013): “Credit within the Firm,” Review of Economic Studies, 80, 211-247.

HAusmann, R., J. HWANG, AND D. RODRIK (2007): "What you export matters," Journal of Economic Growth, 12, 1-25.

LI, Z. AND M. YU (2009): "Exports, Productivity, and Credit Constraints: A Firm-Level Empirical Investigation of China," Global COE Hi-Stat Discussion Paper Series gd09-098, Institute of Economic Research, Hitotsubashi University.

MANOVA, K., S.-J. WeI, AND Z. ZhANG (2011): "Firm Exports and Multinational Activity Under Credit Constraints," NBER Working Papers 16905, National Bureau of Economic Research, Inc.

Manova, K. And Z. Zhang (2012a): "Export Prices across Firms and Destinations," Quarterly Journal of Economics, 127, 379-436.

(2012b): "Multi-Product Firms and Product Quality,” NBER Working Paper 18637, National Bureau of Economic Research.

Mayer, T. and G. Ottaviano (2008): "The Happy Few: The Internationalisation of European Firms," Intereconomics: Review of European Economic Policy, 43, 135-148.

MAYER, T. AND S. ZignAGO (2005): "Market access in global and regional trade," Working paper, 2005/02, CEPII research center.

MinetTi, R. AND S. C. ZHU (2011): "Credit constraints and firm export: microeconomic evidence from Italy,” Journal of International Economics, 83, 109-125. 
Muuls, M. (2008): “Exporters and Credit Constraints. A Firm-Level Approach,” Working Paper Research 2008-139, National Bank of Belgium.

Panetta, F. (2013): “Banks, Finance, Growth,” mimeo, Bank if Italy.

PanetTa, F., F. Schivardi, And M. Shum (2009): "Do mergers improve information? Evidence from the loan market," Journal of Money, Credit and Banking, 41, 673-709.

PAPKe, L. E. AND J. M. WoOldRIDGE (2008): "Panel data methods for fractional response variables with an application to test pass rates," Journal of Econometrics, 145, 121-133.

Paravisini, D., V. Rappoport, P. Schnabl, and D. Wolfenzon (2011): "Dissecting the Effect of Credit Supply on Trade: Evidence from Matched Credit-Export Data," NBER Working Papers 16975, National Bureau of Economic Research, Inc.

SEMYKINA, A. AND J. M. WoOLDRIDGE (2010): "Estimating panel data models in the presence of endogeneity and selection,” Journal of Econometrics, 157, 375-380.

Serti, F. AND C. TOMASI (2012): "Self selection among different export markets," Economics Letters, 117, 102-105.

Timoshenko, O. A. (2012): "Product Switching in a Model of Learning," Working Papers 2012-10, The George Washington University, Institute for International Economic Policy.

WAGNER, J. (2012): “Credit constraints and export: evidence from German manufacturing enterprises,” Working Papers in Economics 251, University of Luneburg.

WoOLDRIDGE, J. M. (2009): “On estimating firm-level production functions using proxy variables to control for unobservables," Economics Letters, 104, 112 - 114. 


\section{Technical Appendix to The micro patterns of export diversification under financial constraints}

\section{Introduction}

This Technical Appendix contains Tables and Figures that complement the results shown in the paper "The micro patterns of export diversification under financial constraints". It also presents a description of some of the estimation methods employed in the work, excluded from the text body for space considerations.

\section{Representativeness}

Our dataset covers about $55 \%$ of all manufacturers that do export (column 1 and 2 in Table 1) and around $85 \%$ of aggregate Italian exports (column 3 and 4 in Table 1). Table 2 shows that the representativeness of the dataset is quite satisfactory. We report here 2003 data, but figures are comparable in the other years. Although the dataset includes only about $20 \%$ of manufacturing in terms of number of firms, we cover about $55 \%$ of manufacturing firms that do export, and about $85 \%$ of the total value of manufacturing exports. These numbers are also fairly stable across different industrial sectors.

This picture is explained by the well known abundance of micro and small firms in Italian manufacturing, together with the observation that the legal status of limited firm tend to be more common across medium-bigger firms, and medium-big firms are expected to account for the great bulk of overall export activities in the country, in line with a well established result in the literature. In agreement with this, Table 3 shows (again for 2003 but valid across other sample years) that the firms in our sample are on average slightly bigger and more productive (in terms of labour productivity, as sales per employee) than in the population of manufacturing firms as resulting from the Italian register of all active manufacturing firms (ASIA dataset). At the same time, however, we do not observe big differences when we focus on exporting firms: the average size, labour productivity, export values, number of exported products and number of destinations served do not differ significantly between our sample and the population. 


\section{The Fligner-Policello test}

In Section 3 and Section 5 of the paper we perform distributional comparisons of FC and NFC firms through the Fligner-Pollicello (FP) test of stochastic dominance. The test is a non parametric procedure robust to various forms of asymmetries and to heteroskedasticity in the samples. In our case, if one denotes with $\mathbf{X}_{F C} \sim F_{F C}$ and $\mathbf{X}_{N F C} \sim F_{N F C}$ two random variables, and with $X_{F C}$ and $X_{N F C}$ two corresponding realizations, then $F_{N F C}$ is said to dominate $F_{F C}$ if $\operatorname{Prob}\left\{X_{N F C}>X_{F C}\right\}>1 / 2$. To assess which of the two distributions dominates the other, Fligner and Policello (1981) suggest to formulate a test as

$$
H_{0}: \int d F_{N F C} F_{F C}=\frac{1}{2} \quad \text { vs } \quad H_{1}: \int d F_{N F C} F_{F C} \neq \frac{1}{2}
$$

In case of rejection of the null, the sign of the Fligner-Policello statistic tells which group is dominating: a negative (positive) sign means that the NFC firms are more (less) likely to display a higher value of $\mathrm{X}$ as compared to $\mathrm{FC}$ firms.

\section{Product and Country extensive margins: controlling for endo- geneity}

We provide here a further robustness check, combining instrumental variable (IVs) and the Semykina and Wooldridge (2010) procedure to also cure endogeneity of the FCs dummy, at least in our two firm-level regressions (Equation 1 and 3 in the paper). In the absence of firm-level instruments, we follow a common approach in the empirical literature on Italy, originally proposed in (Guiso et al., 2004, 2006). The core idea is to exploit an exogenous change in the regulation of the Italian banking services occurred in the 90s to identify exogenous changes in the geographical distribution of credit availability across Italian provinces. Accordingly, we instrument the FC dummy with the 1990-1999 difference in the number of bank branches (per 1,000 inhabitants) in each province. Details on the construction and the validity of the instrument are reported in Secchi et al. (2014) where we apply the same dataset and methodology in the context of the analysis of firms' export intensive margin. Minetti and Zhu (2011) exploit a similar methodology to instrument their survey-based measure of firm-level financial constraints.

Results in Table4 confirm that financial constraints induce a significant reduction in the number of products exported and in the number of countries served. The negative effect of FCs is stronger than what we can infer from the simple FE estimates (in the paper). The latter are upward biased (smaller FC coefficient in absolute value), suggesting that the endogenous component of our FC classification associates with an underestimation of the true detrimental effect of being constrained on exporting activities. 


\section{Procedure for the estimation of the dropping regressions}

In estimating the product or country dropping equations we exploit the transaction level disaggregation of the data and employ a modification of the Semykina and Wooldridge (2010) with Tobit selection equation. The advantage is that in this way we do not need an exclusion restriction variable.

In general terms, the model still consists of two equations

$$
\begin{aligned}
Y_{\cdot, t} & =\gamma_{1} F C_{f, t-1}+\boldsymbol{\beta} \mathbf{Z}_{f, t-1}+F E_{1, \cdot}+\epsilon_{1 \cdot t} \\
\operatorname{ExpVal,t} & =\operatorname{Max}\left[0, \gamma_{2} F C_{f, t-1}+\boldsymbol{\delta} \mathbf{Z}_{f, t-1}+F E_{2, \cdot}+\epsilon_{2 \cdot, t}\right],
\end{aligned}
$$

where a "." in the subscript indicates that the variables can be taken at different combination of firmproduct or firm-country level, depending on the precise specification we intend to estimate. In the primary equation the dependent variable of interest (the probability of dropping products or destinations) is regressed against the FC dummy, the firm level controls $\mathbf{Z}_{f}$ and a set of fixed effect $F E_{1}$ controlling for diverse sources of unobserved factors. The selection equation is a Tobit on the (log of the) value of export, ExpVal, with explanatory variables given by the financial status $F C_{f, t-1}$, the firm-level controls and a fixed effect capturing the same type of unobserved heterogeneity modeled in the primary equation. Notice that in this equation the fixed effects are inserted by adding the time averages of the proper explanatory variables, exactly as in the original method in Semykina and Wooldridge (2010).

Consistent estimates are obtained through the following procedure

\section{Procedure 5.1}

1. for each $t$, obtain the residuals from a Tobit estimate of equation (3) augmented with the time averages of firm-level and product-level or country-level controls, depending on the type of fixed effects chosen for the main equation (2);

2. estimate equation (2) with appropriate fixed effects and with the residuals obtained in Step 1 together with their interactions with time dummies;

3. use a "panel bootstrap", sampling across sectional units, to obtain asymptotic standard errors corrected for problems related to general heteroskedasticity and serial correlation.

The estimation of the product-dropping equation (6) in the paper via Procedure 5.1 requires to identify the bundle of products potentially, yet not actually exported by each firms. This is indeed a necessary first step to impute 'zeros' in the dataset, before estimating the Tobit regression. This enormously increases the data dimension, rapidly exceeding feasible computational limits. Since it is not reasonable to assume that each firm can in principle export any of the product present in the dataset, we limit the export choices available to a firm on the basis of affinity of HS categories. This is described in the following procedure:

\section{Procedure 5.2}


1. we define as $P C_{i}$ the product category at the level of HS4 sections;

2. for each category $P C_{i}$, we identify the set $F_{P C_{i}}$ of all the firms exporting at least one HS6 product inside the $P C_{i}$;

3. we define a product list, $P L_{P C_{i}}$, containing all the different products exported by the firms in $F_{P C_{i}}$

4. to each firm in $F_{P C_{i}}$, we assign the value of her export in each product of the list $P L_{P C_{i}}$ if a transaction of that firm in that product exists in the data, and a 0 otherwise;

5. we repeat steps 2-4 for each $P C_{i}$ category, and then merge all the data.

At the end of these steps, we remain with a dataset of 9,871,750 observations.

We do not have a similar conceptual problem in estimating the destination-drop equation (7), as it is indeed more reasonable to assume that a firm can in principle serve any of the available countries. In this case, however, a computational problem emerges generated by the high number of possible destinations. To overcome the issue, we rank all the destination countries according to their value of export and then cut out the bottom $50 \%$ of the distribution. This seemingly drastic cut removes less than $0.5 \%$ of the total value of the Italian export. At the end of this procedure we remain with a dataset of $16,890,120$ observations. 
Table 1: REPRESENTATIVENESS OF THE SAMPLE

\begin{tabular}{cccccc}
\hline & \multicolumn{2}{c}{ Number of exporters } & & \multicolumn{2}{c}{ Export value (Bill. euros) } \\
\cline { 5 - 6 } Year & Universe & Our sample & & Universe & Our sample \\
\hline 2000 & 78,412 & 44,955 & & 209.9 & 176.9 \\
2001 & 79,577 & 46,364 & & 223.8 & 192.9 \\
2002 & 80,593 & 47,076 & & 220.9 & 190.6 \\
2003 & 79,356 & 46,492 & & 218.1 & 182.9 \\
\hline
\end{tabular}

Notes: Number of exporting firms and total exports for the universe of manufacturing exporters (COE dataset) and for our sample (matched COE-CB dataset).

Table 2: COVERAGE OF THE DATASET, MANUFACTURING: NUMBER OF FIRMS; NUMBER OF EXPORTERS, EXPORT VALUE (2003)

\begin{tabular}{|c|c|c|c|c|c|c|c|c|c|}
\hline \multirow[b]{2}{*}{ Sector } & \multicolumn{3}{|c|}{ ALL FIRMS } & \multicolumn{3}{|c|}{ EXPORTERS } & \multicolumn{3}{|c|}{ EXPORT VALUE } \\
\hline & $\begin{array}{l}\text { ASIA-COE } \\
\text { (Number) }\end{array}$ & $\begin{array}{c}\text { Our dataset } \\
\text { (Number) }\end{array}$ & $\begin{array}{c}\text { Coverage } \\
\% \\
\end{array}$ & $\begin{array}{l}\text { ASIA-COE } \\
\text { (Number) }\end{array}$ & $\begin{array}{c}\text { Our dataset } \\
\text { (Number) }\end{array}$ & $\begin{array}{c}\text { Coverage } \\
\% \\
\end{array}$ & $\begin{array}{l}\text { ASIA-COE } \\
\text { (billion) }\end{array}$ & $\begin{array}{c}\text { Our dataset } \\
\text { (billion) }\end{array}$ & $\begin{array}{c}\text { Coverage } \\
\% \\
\end{array}$ \\
\hline 15 & 71345 & 8882 & 12.45 & 4927 & 2872 & 58.36 & 12.1 & 9.4 & 77.77 \\
\hline 17 & 27762 & 6408 & 23.08 & 5681 & 3445 & 60.69 & 12.5 & 10.8 & 86.70 \\
\hline 18 & 41615 & 6134 & 14.74 & 5035 & 2654 & 52.73 & 9.7 & 8.1 & 83.56 \\
\hline 19 & 21985 & 4495 & 20.45 & 5688 & 2644 & 46.48 & 10.8 & 8.8 & 81.62 \\
\hline 20 & 46584 & 3550 & 7.62 & 2458 & 978 & 39.79 & 1.5 & 1.3 & 83.88 \\
\hline 21 & 4566 & 1951 & 42.73 & 1328 & 884 & 66.57 & 4.0 & 3.8 & 95.28 \\
\hline 22 & 27344 & 7801 & 28.53 & 2164 & 1237 & 57.26 & 1.7 & 1.6 & 91.25 \\
\hline 23 & 443 & 333 & 75.17 & 84 & 72 & 86.90 & 3.8 & 3.7 & 99.25 \\
\hline 24 & 6127 & 3529 & 57.60 & 2595 & 1984 & 76.61 & 22.6 & 16.3 & 71.80 \\
\hline 25 & 13084 & 5575 & 42.61 & 4422 & 2968 & 67.18 & 10.4 & 8.9 & 85.72 \\
\hline 26 & 27230 & 6218 & 22.84 & 4522 & 2176 & 48.12 & 7.2 & 6.2 & 86.18 \\
\hline 27 & 3814 & 1893 & 49.63 & 1335 & 1016 & 76.10 & 9.9 & 8.7 & 88.21 \\
\hline 28 & 99519 & 19551 & 19.65 & 10280 & 5754 & 56.17 & 12.6 & 11.2 & 89.26 \\
\hline 29 & 42391 & 14710 & 34.70 & 12128 & 8177 & 67.55 & 43.3 & 38.0 & 87.61 \\
\hline 30 & 1976 & 822 & 41.60 & 262 & 185 & 70.61 & 1.5 & 1.3 & 91.19 \\
\hline 31 & 18316 & 5315 & 29.02 & 3214 & 2128 & 66.30 & 8.1 & 6.6 & 82.12 \\
\hline 32 & 8671 & 1665 & 19.20 & 911 & 608 & 66.85 & 5.2 & 3.7 & 71.02 \\
\hline 33 & 22399 & 3073 & 13.72 & 1921 & 1355 & 70.68 & 4.6 & 3.9 & 85.18 \\
\hline 34 & 1962 & 1122 & 57.19 & 918 & 687 & 74.84 & 17.8 & 15.3 & 85.86 \\
\hline 35 & 4684 & 1541 & 32.90 & 819 & 475 & 60.81 & 6.7 & 4.9 & 73.84 \\
\hline 36 & 50018 & 7873 & 15.74 & 8664 & 4193 & 48.42 & 12.1 & 10.4 & 85.96 \\
\hline Total & 541835 & 112441 & 20.75 & 79356 & 46492 & 58.69 & 218.1 & 183.0 & 83.93 \\
\hline
\end{tabular}

Notes: The Table reports, for 2003, the number of firms, the number of exporters and the export value by sector for the entire population of Italian manufacturing firms (COE dataset) and the limited liabilities firms (our dataset). 


\begin{tabular}{lcccccc}
\hline & \multicolumn{3}{c}{ ASIA-COE } & \multicolumn{3}{c}{ Our Dataset } \\
& Mean & Sd & Observations & Mean & Sd & Observations \\
\hline log number of employees & 2.43 & 1.35 & 79356 & 2.85 & 1.32 & 46492 \\
log export & 11.61 & 2.74 & 79356 & 12.43 & 2.67 & 46492 \\
Number of products & 8.04 & 14.7 & 79356 & 10.8 & 17.0 & 46492 \\
Number of destinations & 8.77 & 12.9 & 79356 & 11.7 & 14.7 & 46492 \\
\hline
\end{tabular}

Notes: The Table reports, for 2003, basic descriptive statistics for the entire population of Italian manufacturing exporting firms (ASIA-COE dataset) and for limited liabilities firms (our dataset).

Table 4: Financial Constraints and Product-Country Extensive margin

\begin{tabular}{|c|c|c|}
\hline & $\begin{array}{c}\ln \# \text { Products }_{f, t} \\
\text { (1) }\end{array}$ & $\begin{array}{c}\ln \# \text { Countries }_{f, t} \\
\text { (2) }\end{array}$ \\
\hline \multirow{2}{*}{$F C_{f, t-1}$} & $-0.719^{*}$ & $-1.250 * *$ \\
\hline & $(0.345)$ & $(0.595)$ \\
\hline \multirow[t]{2}{*}{$\ln T F P_{f, t-1}$} & -0.035 & -0.062 \\
\hline & $(0.035)$ & $(0.039)$ \\
\hline \multirow[t]{2}{*}{$\ln E m p l_{f, t-1}$} & -0.029 & -0.041 \\
\hline & $(0.032)$ & $(0.036)$ \\
\hline \multirow[t]{2}{*}{$\ln A g e_{f, t}$} & 0.067 & $0.139 * *$ \\
\hline & $(0.060)$ & $(0.066)$ \\
\hline \multirow[t]{2}{*}{$\ln A S S E T S_{f, t-1}$} & $0.208 * * *$ & $0.178 * * *$ \\
\hline & $(0.026)$ & $(0.029)$ \\
\hline \multirow[t]{2}{*}{$\ln G O M_{f, t-1}$} & -0.016 & $-0.031 * *$ \\
\hline & $(0.013)$ & $(0.014)$ \\
\hline Year FE & Yes & Yes \\
\hline Firm FE & Yes & Yes \\
\hline R-squared & 0.257 & 0.285 \\
\hline N.Observations & 95,075 & 95,075 \\
\hline
\end{tabular}

Note: The dependent variable is the (log) number of products exported (column 1) or destinations served (column 2). $F C_{f, t-1}$ is a dummy for financially constrained firms. All the regressions include a constant term. Robust standard errors clustered at firm level are reported in parenthesis below the coefficients. Asterisks denote significance levels (***:p $<1 \% ; * *: \mathrm{p}<5 \%$; $: \mathrm{p}<10 \%)$.

\section{References}

Fligner, M. A. And G. E. Policello (1981): "Robust rank procedures for the Behrens-Fisher problem," Journal of the American Statistical Association, 76, 141-206.

Guiso, L., P. SAPIENZA, AND L. Zingales (2004): "Does Local Financial Development Matter?" The Quarterly Journal of Economics, 119, 929-969.

(2006): “The Cost of Banking Regulation,” NBER Working Papers 12501, National Bureau of Economic Research, Inc. 
Minetti, R. AND S. C. ZHU (2011): "Credit constraints and firm export: microeconomic evidence from Italy," Journal of International Economics, 83, 109-125.

Secchi, A., F. TAmagni, And C. TOMASI (2014): "Financial constraints and firm exports: accounting for heterogeneity, self-selection and endogeneity," LEM Working Papers n. 2014-16, Scuola Superiore Sant'Anna, Pisa, Italy.

SEMYKINA, A. AND J. M. WoOLDRIDGE (2010): "Estimating panel data models in the presence of endogeneity and selection,” Journal of Econometrics, 157, 375-380. 